\title{
فاعلية استخداه موقع تعليمي تفاعلي في تنمية التحصيل ومهارات التفكير البصري للى طالبات الصف الحادي عشر في مادة التزبية الإسلامية بسلطنة عمان
}

\author{
رابعة الصقرية * و محسن السالمي
}

Doi: //10.47015/17.3.5

\section{The Effectiveness of Using an Interactive} Learning Website on Developing Achievement and Visual Thinking Skills among Grade - 11 Female Students in the Islamic Education Subject in Oman

Rabea Al-Sqria, The Ministry of Education, Sultanate of Oman.

Mohsin Al-Salmi, Sultan Qaboos University, Sultanate of Oman.

Abstract: This study aimed to identify the effectiveness of using an interactive learning website on developing achievement and visual thinking skills among grade - 11 students in the Islamic education subject in Oman. The study sample consisted of (62) female students, divided into two groups: the experimental group included (30) and the control group included (32) students. The researchers followed the quasi-experimental approach. In order to achieve the study aim, an achievement test consisting of (20) questions was prepared. The validity of its content was verified by presenting it to a group of arbitrators. As for its reliability, it reached (0.72). The visual thinking skills test was used; it contained of five skills covered by (23) questions. A group of arbitrators verified the validity of its content and its reliability reached $(0.70)$. The study results showed that there were statistically significant differences at the level of (0.05) between the students' mean scores in the experimental and control groups in the achievement test and the visual thinking test in favor of the experimental group that was taught using the interactive learning website.

(Keywords: Interactive Learning Website, Achievement, Visual Thinking Skills, Islamic Education)

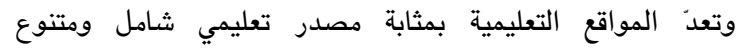

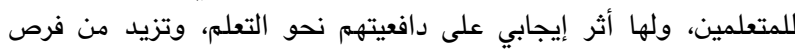

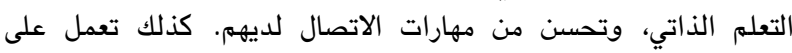

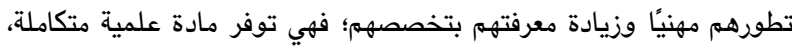

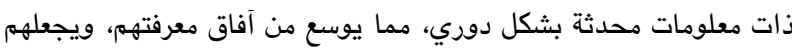
أكثر قدرة على إثراء مادتهم العلمية (Sharp, 2000) .
ملخص: هدفت الدراسة الحالية إلى الكثف عن فاعلية استخدام موقع تعليمي

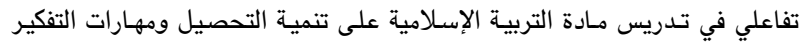

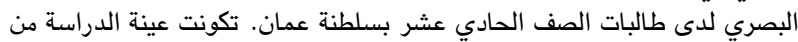

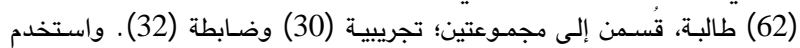

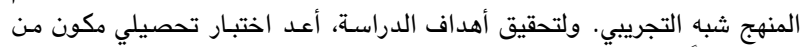

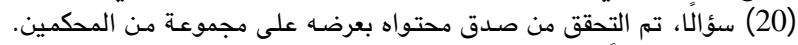

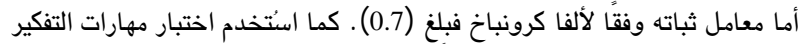

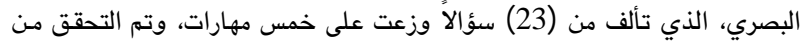

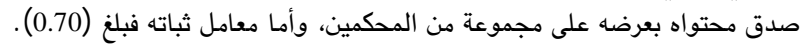

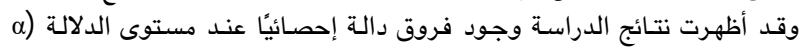

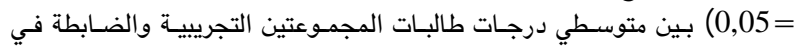

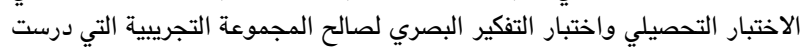
باستخدام الموقع التعليمي التفاعلي.

(الكلمات المفتاحيـة: موقع تعليمي تفاعلي، التحصيل، مهارات التفكير البصري،

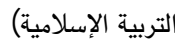

مقدمة: يشهد تدريس التربية الإسلامية اهتمامًا كبيرًا وتطورًا

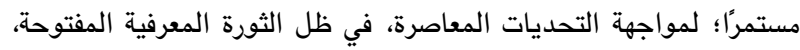

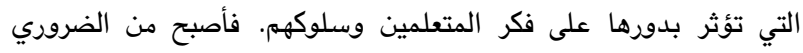

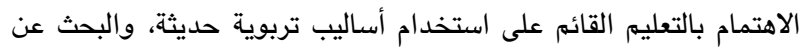

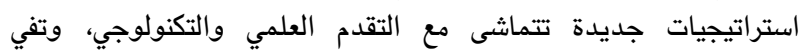

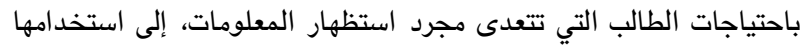
وتوظيفها في مواتف جديدة (Abu Khousa, 2014).

وتعد الاستراتيجيات الحديثة في التدريس القائمة على التكنولوجيا

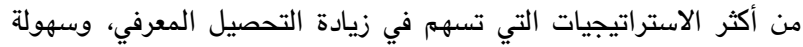

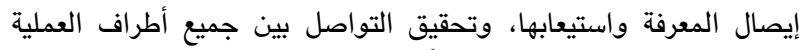

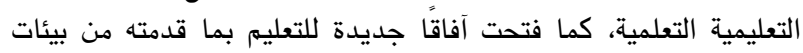
تعليمية إلكترونية تعتمد على توظيف تقانة الحواسيب، واستخدام

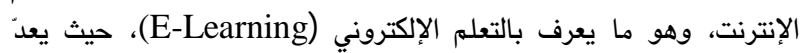

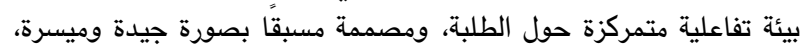

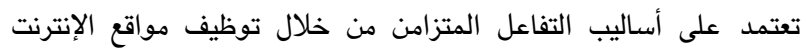

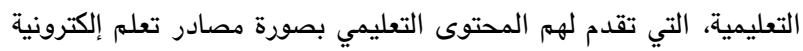
تقوم على استخدام الوسائط المتعددة (Al-Shawadfi, 2011) .

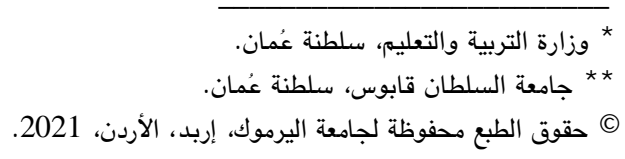


الدراسة من (36) طالبًا، وقد صُمْمَ موقع تعليمي درَّس من خلاله

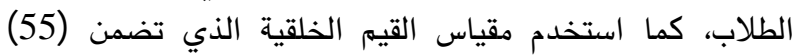

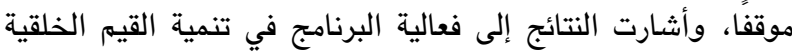

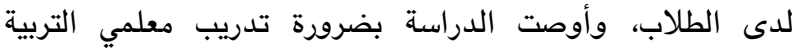
الإسلامية ومعلماتها على استراتيجيات التعلم المدمج؛ لأثرها الفعال

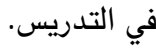

كما أجرى سلامة (Salamah, 2011) دراسة هدفت إلى إلى

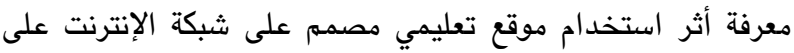

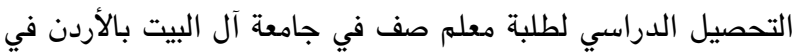
مساق مناهج التربية الإسلامية. تكونت عينة الدراسة من البه (112)

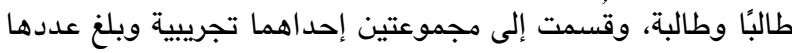

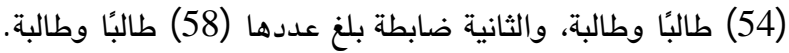

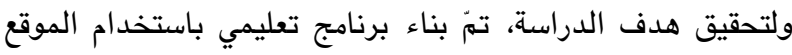

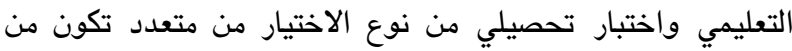

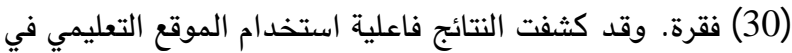

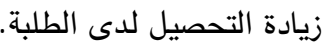
وهدفت دراسة الزعبي (Al-Zoubi, 2007) إلى معرفة أثر الأثر

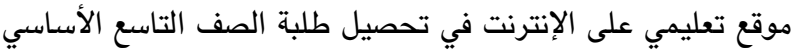

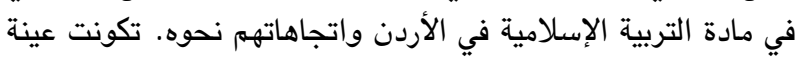

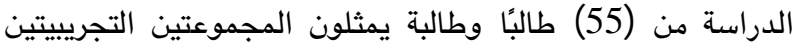

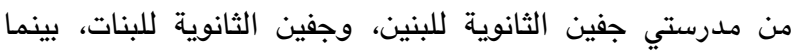

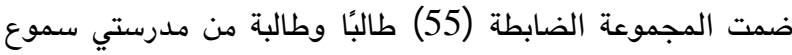

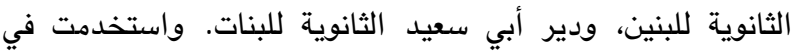

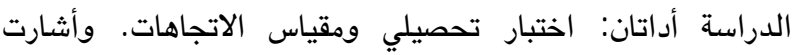

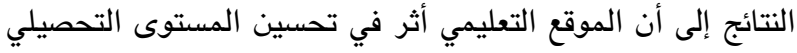
للطلبة، وكوّن اتجاهات إيجابية نحو استخدام الموقع التعليمي. إن الاتجاهات الحديثة نحو استخدام التقانة الحديثة كان لها

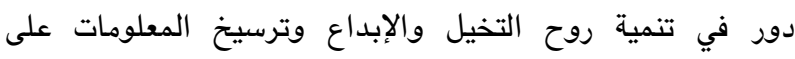
اختلاف أنواعها، عن طريق الوسائل التوائل المتاحة، كالصور الثابت الثابتة

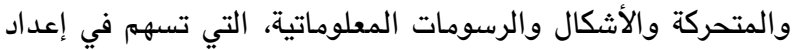

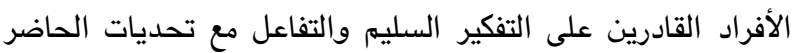
ومتطلباته ومتغيرات المستقبل. ويعدّ التفكير ومهاراته المختلفة أمرًا ضروريًا في جميع نواحي الإني

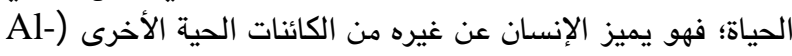
(Tarawnah, 2014 والمناهج الحديثة في كثير من الدول تولي مهارات التفكير المزيد التاتيد

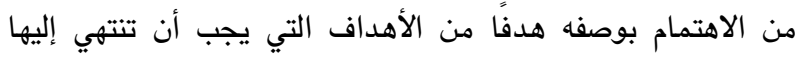

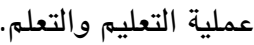

ومن أهم مهارات التفكير التي يسعى التربويون إلى تنميتها

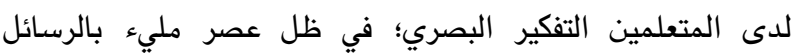

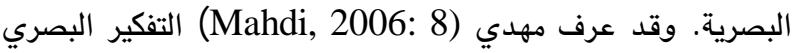
بأنه "منظومة من العمليات تترجم قدرة الفرد :8رد على قراءة الشكل
ويُعرت علي (Ali, 2006) 148) المواقع التعليمية بأنها

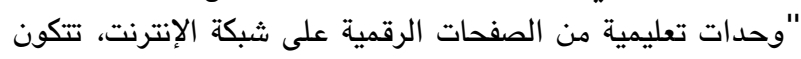

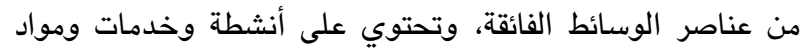

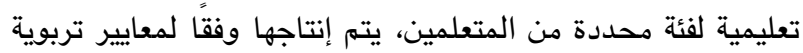

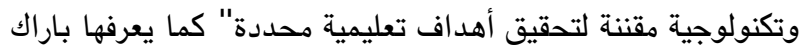
وزيف (Barak and Ziv, 2013: 159) بأنها "بيئات تعليمية

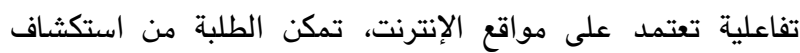

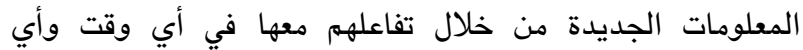

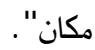

وتعدّ المواقع الإلكترونية بيئة تعليمية تفاعلية يقدم فيها المحتوى بصورة صفحات رقمية متصلة على شبكة الإنترنت، وعلى الإلى الوسائط المتعددة التي يتفاعل معها الطلبة، لتحقيق الأهداف

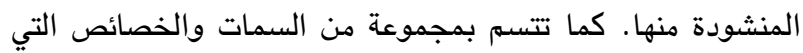

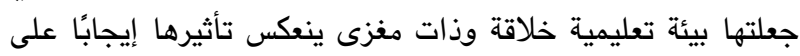

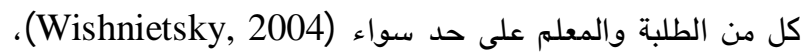
فتعمل على استثارة دافعية الطلبة نحو التعله، كما تتمي لديهم الطماء المهارات ما وراء المعرفية، وتوفر لهم مجموعة من الأنثطة

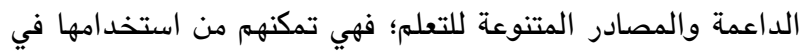

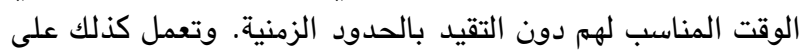

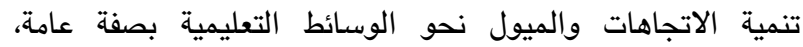

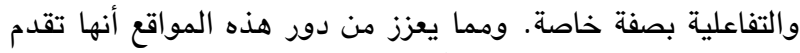
تغذية راجعة فورية للطلبة تمكنهم من معرفة مدى تقدمهنم، والعمل على تحسين تحصيلهم الدراسي (Al-Senaidi, 2014). وتؤدي المواقع التعليمية دورًا حيويًا في العملية التعليمية،

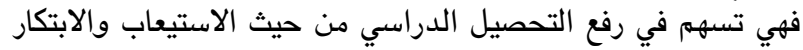

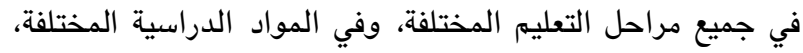

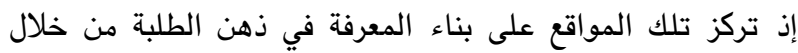

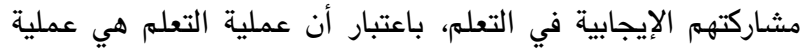
بنائية نشطة. كذلك تتيح تقديم التفذية الراجعة الفورية في أثناء التهاء

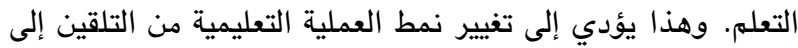

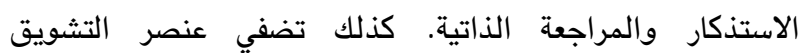

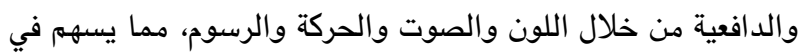
إشراك أكبر عدد من الحواس في أثناء عملية التعلم، فيؤدي ذلك الك الكي

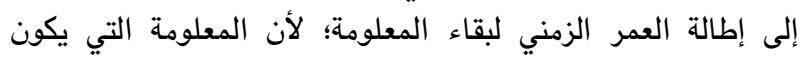

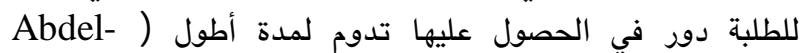
. (Gawad, 2014

وقد أكدت العديد من الدراسات أن التدريس باستخدام

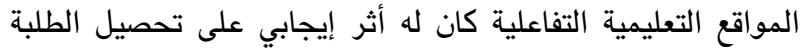

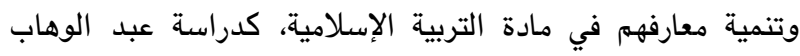

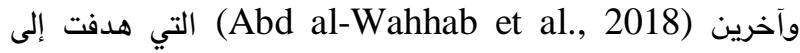
معرفة أثر برنامج قائم على التعلم المدمج في التربية الإسلامية في

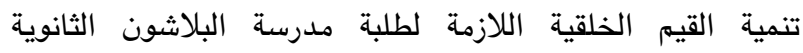
المشتركة في محافظة الشرقية بجمهورية مصر العربية. تكونت عينة 
الرؤية الفاحصة للمثيرات البصرية، كالرسوم والأشكال التوضيحية

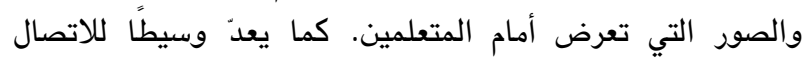

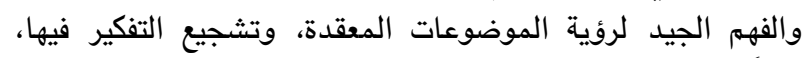
فضلًا على قدرته في تحسين اتصال المتعلمين بالآخرين، وإكسابهم

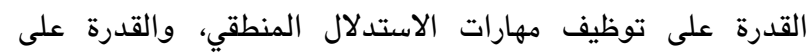
التخيل (Jabr, 2010 ; Al- Agha, 2015). ونظرًا لأهمية الأدية التفكير البصري، فقد تناولته دراسات عدة منها: دراسة الحربي

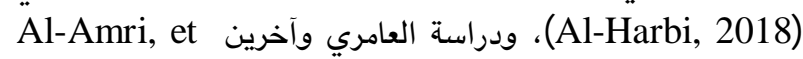

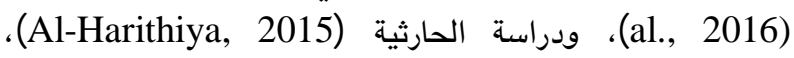
Al-Khazndar and Mahdi, ) ودراسة الخزندار ومهدية ودراسة) 2006)، ودراسة إبراهيم (Ibrahim, 2006).

وتعدّ مهارات التفكير البصري من المهارات الأساسية التي

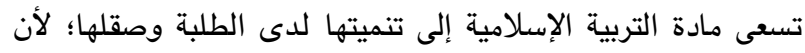
مصدري التشريع - القرآن الكريم والسنة النبوية إلمي تصيتها - استخدم فيهما هذا النوع من التفكير من خلال استخدام الصور التوضيحية،

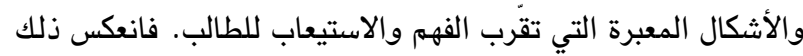

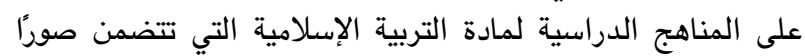

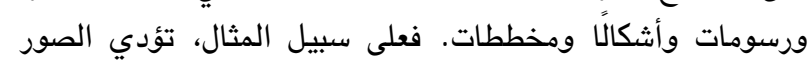

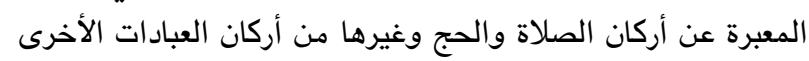

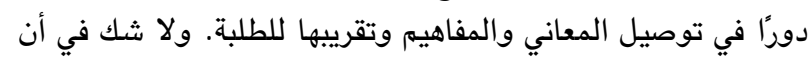

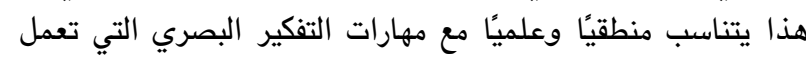
على أخذ صورة ذهنية عن طريق حاسة البصر، والتعبير عنها بصريًا

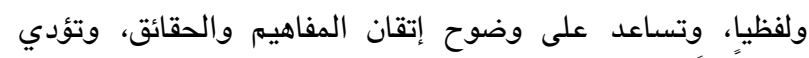

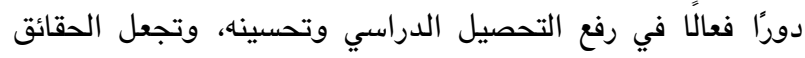

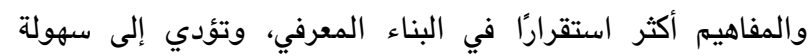

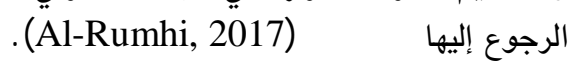

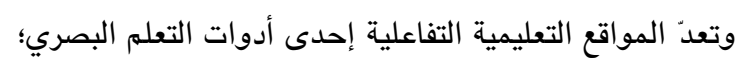

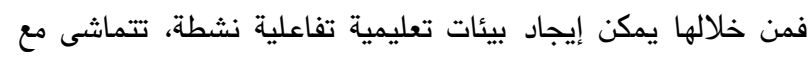
توجهات الطلبة واهتماماتهم، فيحصل الطلبة على صور وأشكال

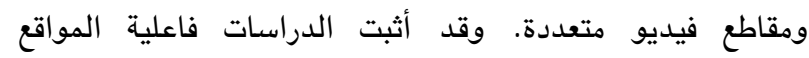
التعليمية التفاعلية في تنمية التفكير البصري، ومن ذلك دراسة أبو

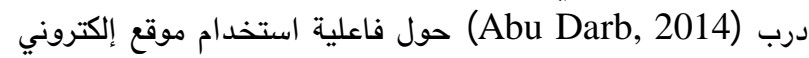
تفاعلي لتنمية التحصيل المعرفي والتفكير البصري في الدراسات فاعلية الإني

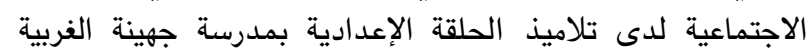

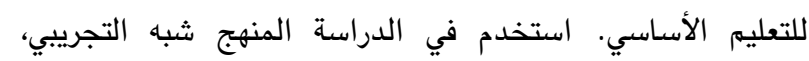

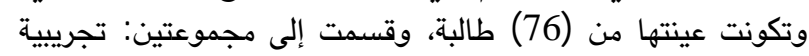

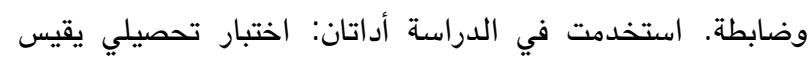

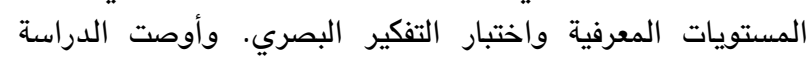

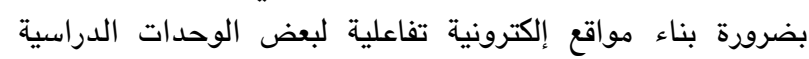

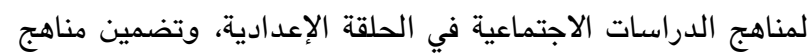

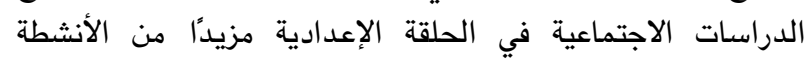

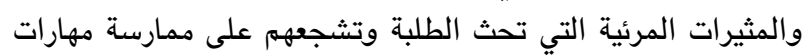

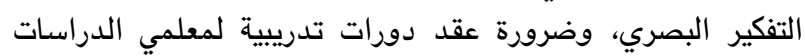

البصري، وتحويل اللغة البصرية التي يحملها ذلك الثكل إلى لفة لفظية (مكتوبة أو منطوقة)، واستخلاص المعلومات منه"، في حين

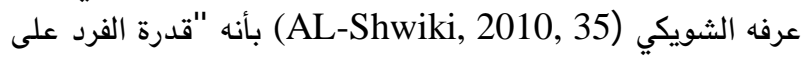

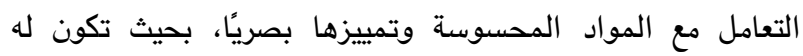

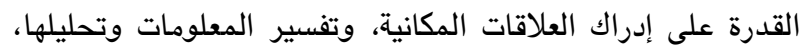
وكذلك تفسير الفموض واستنتاج المعني بها ".

والتفكير البصري من أرقى مستويات التفكير؛ لأنه يجمع بين

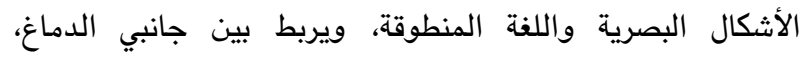

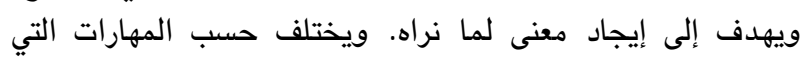
يعالجها، لذلك يسعى التربويون إلى الاهتمام بتنمية مهاراته في أثناء

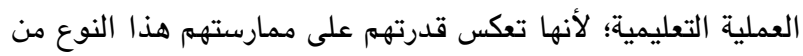
التفكير · وهناك عدة مهارات يقوم عليها التفكير البصري، وهي عبارة

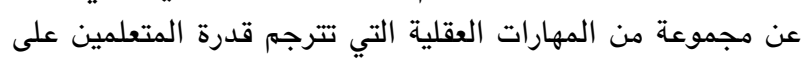

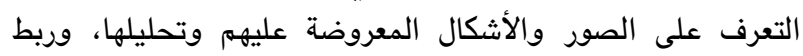
العلاقات فيها وإدراكها، واستخلاص المعنى منها ( Al-Busaidia, . 2017

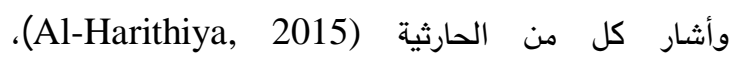
والقحطاني (Al-Qahtani, 2015)، ومهدي (Mahdi, 2006) إلى المهارات التي يقوم عليها التفكير البصري، وهي: 1. مهارة التعرف على الثكل ووصفه: القدرة على تحديد أبعاد الشكل المعروض وطبيعته.

2. مهارة تحليل الثكل: القدرة على رؤية العلاقات في الثكل، وتحديد خصائص تلك العلاقات وتصنيفها .

3. مهارة إدراك العلاقات في الثكل: القدرة على الربط بين عناصر

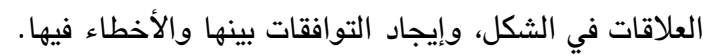

4. مهارة إدراك الغموض وتفسيره: القدرة على توضيح الفجوات والأخطاء بين العناصر وتقريب العلاقات بينها.

5. مهارة استخلاص المعنى: القدرة على استنتاج معاني جديدة،

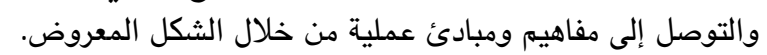

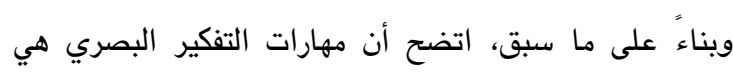

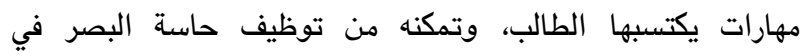
التعرف على الشكل وتمييزه عن غيره من الأشكال، وإيضاح

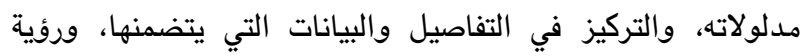

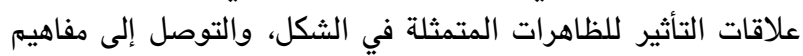
واستخلاص معاني جديدة من خلاله.

وتكمن أهمية التفكير البصري في قدرته على بناء المعلومات

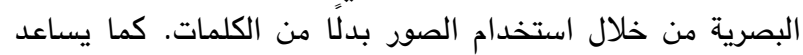
المتعلمين على اكتساب مهارة حل المشكلات (Saleh, 2012).

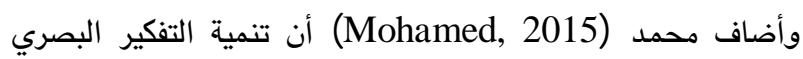
هدف لأي نظام تعليمي؛ فمن خلاله يمكن استخلاص المعلومات

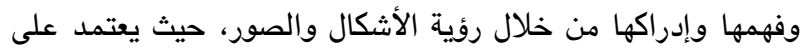


ذلك على تحصيل الطلبة. كذلك فإن طرق التدريس المتبعة ما زالت تعتمد على الحفظ والتلقين أكثر من تنميتها مهارات التفكير لدى الكى

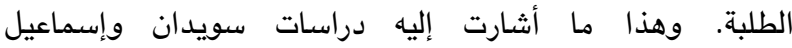
Al-) والصيل (Saqriyah, 2018 )، وأبو شريعة (Abu Sharia, 2015)، ونظرًا لقلة الدراسات التي تناولت المواقع التعليمية التفاعلية

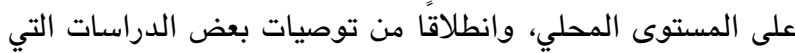

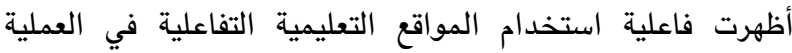

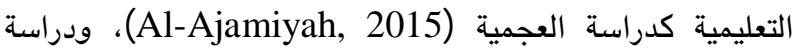

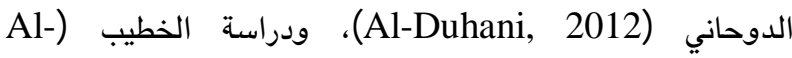
Khatib, 2008 (Kh)، وجد الباحثان أن استخدام الموقع التعليمي

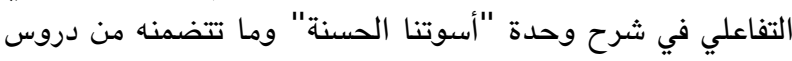

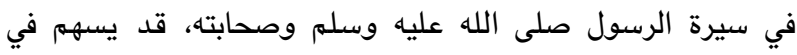

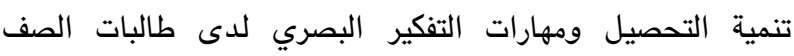

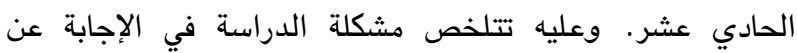

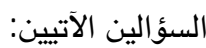

1. ما فاعلية استخدام موقع تعليمي تفاعلي في تدريس مادة التربية

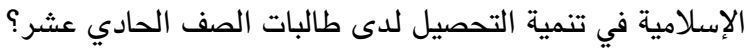

2. ما فاعلية استخدام موقع تعليمي تفاعلي في تدريس مادة التربية

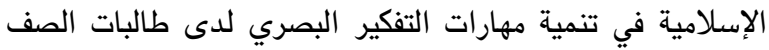

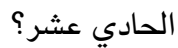

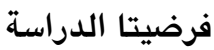

في ضوء السؤالين السابقين، صيغت الفرضيتان الآتيتان:

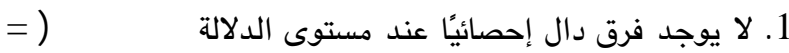

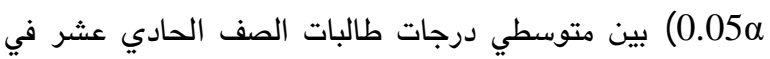

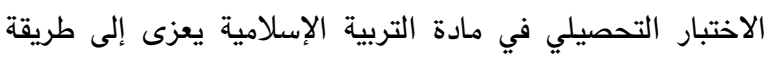
التدريس (الموقع التعليمي التفاعلي، وطريقة التدريس الاعتيادية) في التطبيق البعدي.

2. لا يوجد فرق دال إحصائيًا عند مستوى الدلالة

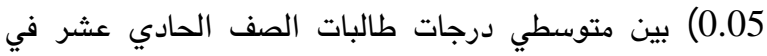

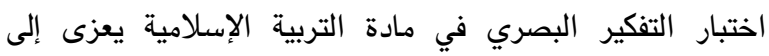

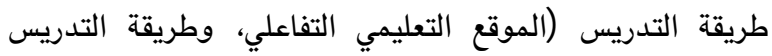
الاعتيادية) في التطبيق البعدي.

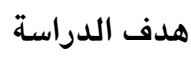

تسعى الدراسة إلى الكثف عن فاعلية استخدام موقع تعليمي

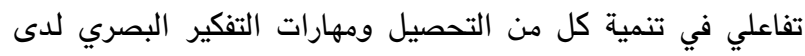
طالبات الصف الحادي عشر في مادة التربية الإسلامية.
الاجتماعية بهدف اكسابهم المهارات اللازمة لاستخدام المواقع الإلكترونية التفاعلية بنجاح في التدريس.

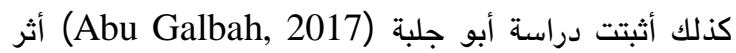

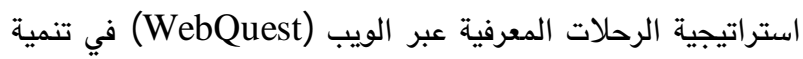

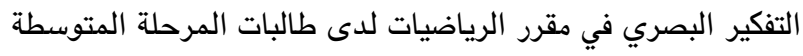

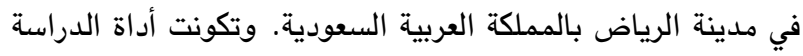

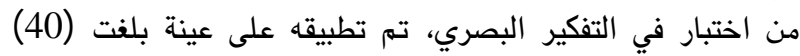

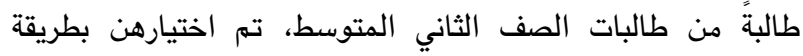

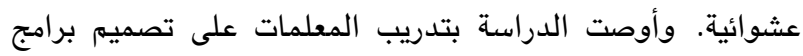

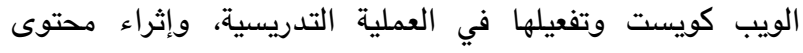

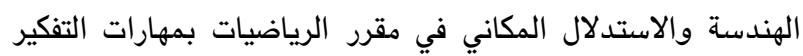

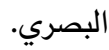

مما سبق، يتبين أن الدراسات السابقة اقتصرت على دراسة

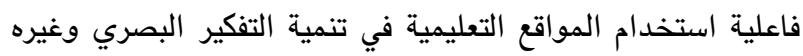

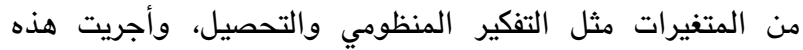

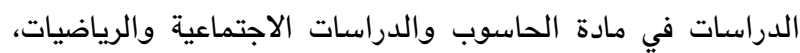

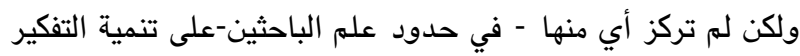

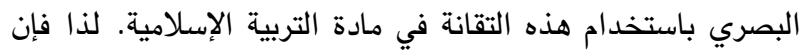

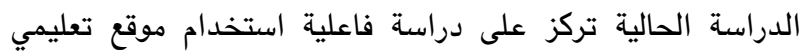
تفاعلي في تنمية التحصيل ومهارات التفكير البصري في مادة الترائ التربية الإسلامية لدى طالبات الصف الحادي عشر بسلطنة عمان.

مشكلة الدراسة وسؤالاها

تعاني مادة التربية الإسلامية من وجود بعض المشكلات التعليمية التي تحول دون تحقيق الأهداف التي تسعى إلى تحتية تحقيقها،

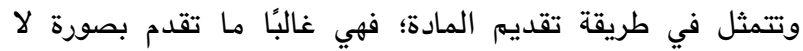

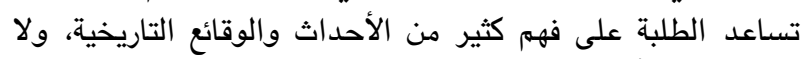

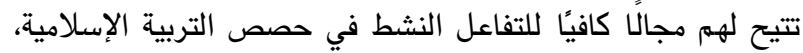

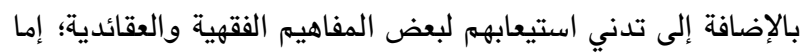

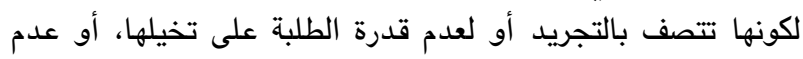

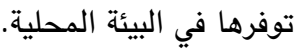

ومن خلال معايشة الباحثين للواقع الميداني، تبين وجود ضعف في تنمية مهارات التفكير البصري في مادة التربية الإسلامية، كتفسير بعض الأحداث التاريخية، وأركان العبادات والثعائر التعبدية فيادية

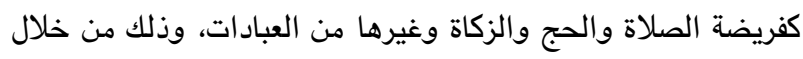

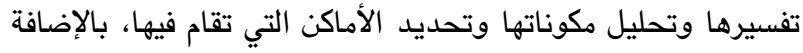

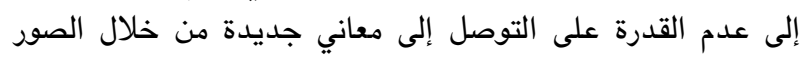

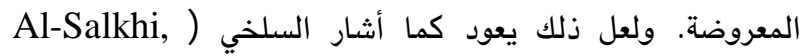

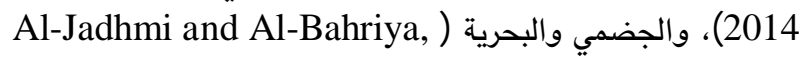

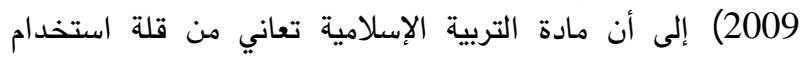
المعلمين للوسائل التعليمية الحسية في تدريس العان العبادات والثية الثعائر

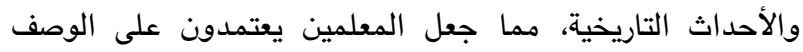

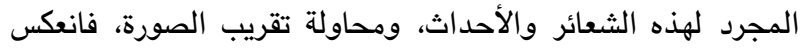


وسائط متعددة تتفاعل معها طالبات الصف الحادي عشر لتحقيق أهداف وحدة " أسوتنا الحسنة ". • التحصيل الدراسي (Academic Achievement): يعرفه اللقاني والجمل (Al-Liqāni \& al-Jamal, 2003: 47) بأنه: (Acade "مدى استيعاب الطلبة لما تعلموه من خبرات معينة من خلال

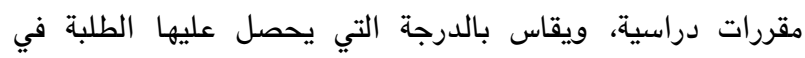

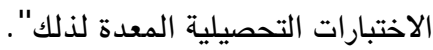

ويُعرَت إجرائيا بأنه: المعلومات والمعارف التي اكتسبتها

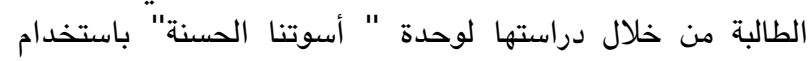

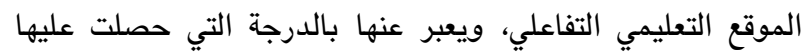
في الاختبار التحصيلي المعد لأغراض الدراسة. • التفكير البصري (Visual Thinking): عرفه عبد الخالق وعبد الخالق :Abdel-Khalek \& Abdel-Khalek, 2008 (186 بأنه "محاولة فهم العالم من خلال لفة الشكل والصورة" . ويُعرَف إجرائيًا بأنه: قدرة الطالبات على التمييز البصري

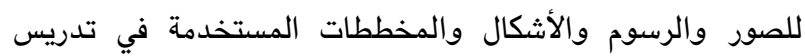

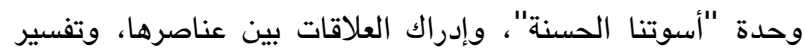

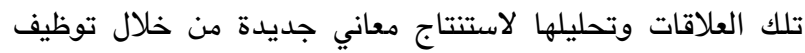

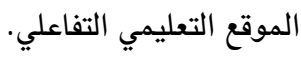

• مهارات التفكير البصري (Visual Thinking Skills)؛

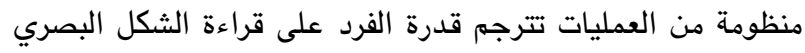

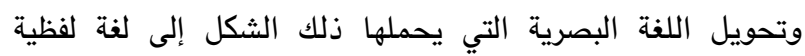

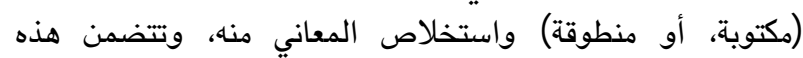

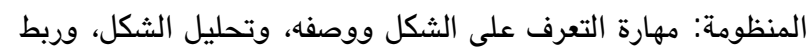

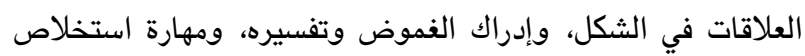
المعاني (Draz, 2007: 153) وتعرف في الدراسة إجرائيًا بأنها: مجموعة من العمليات التي

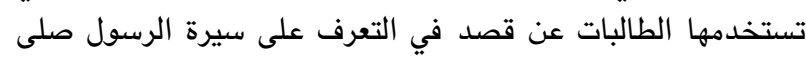

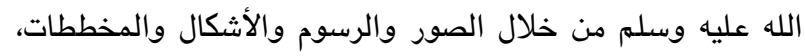

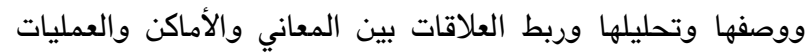

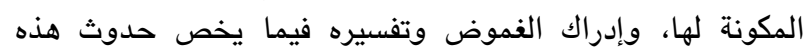

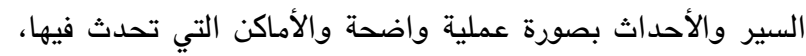

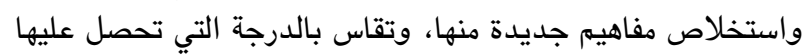
الطالبات في الاختبار المعد لهذا الغرض. وناص.
تكمن أهمية الدراسة الحالية في كونها من أوائل الدراسات

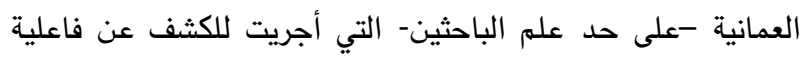

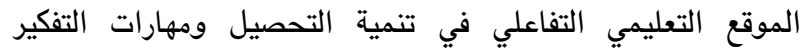

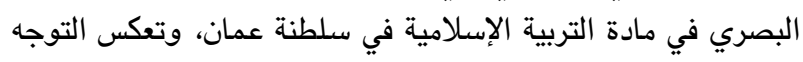

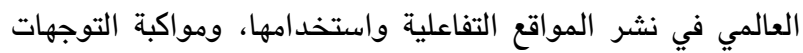

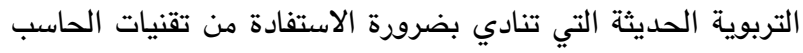

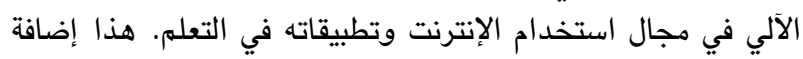

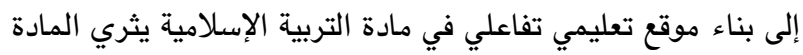

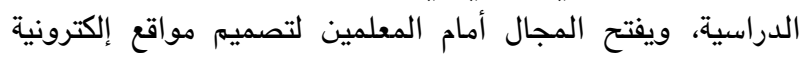

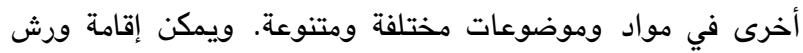

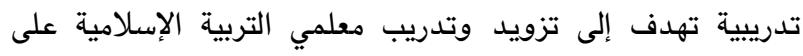

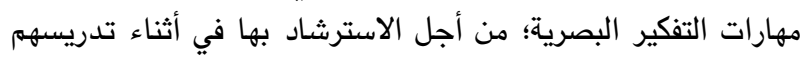

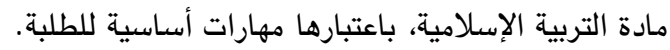

$$
\text { حدود الدراسة }
$$

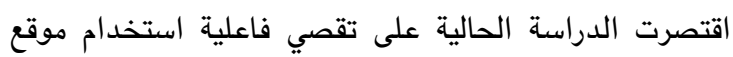

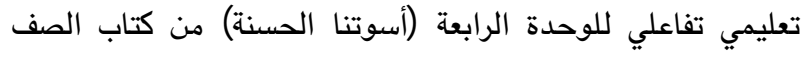

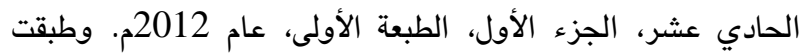

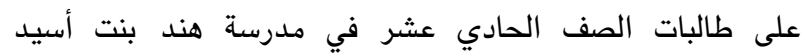

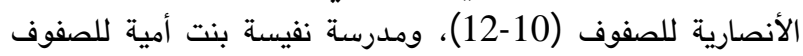
(12-11) في محافظة جنوب الباطنة بسلطنة عمان، خلال الفصل

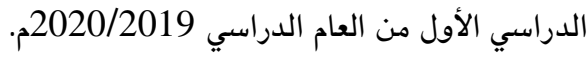

$$
\begin{aligned}
& \text { التعريفات الاصطلاحية والإجرائية }
\end{aligned}
$$

• الفاعلية (Effectiveness): عرفها شحاته والنجار وعمار : بأنها (Shehata, Al-Najjar \& Ammar, 2003: 230) "مدى الأثر الذي يمكن أن تحدثه المعالجة التجريبية باعتبارها

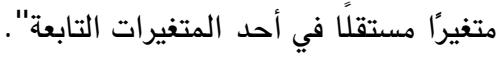

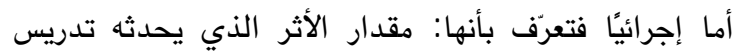

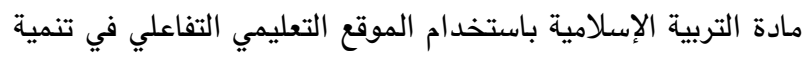
التحصيل والتفكير البصري لدى طالبات الصف الحادي عشر .

• الموقع التعليمي التفاعلي ( Interactive Learning (Websit

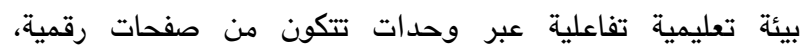

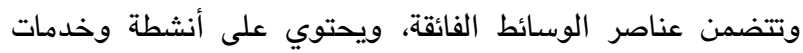

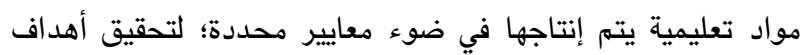

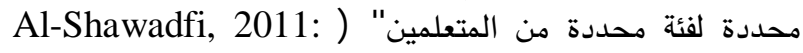

بينما يُعرّف إجرائيًا بأنه: مجموعة من صفحات الويب المتصلة بعضها بواسطة النصوص الفائقة، لتقديم برنامج تعليمي باستخدام 
درنست المجموعـة الضـابطة باستخدام طرائق التـدريس الاعتياديـة،

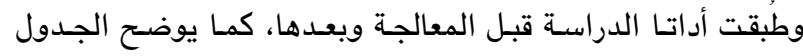

(1)

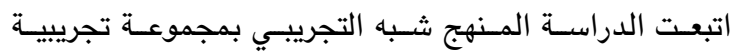
ومجموعة ضابطة، من طالبات الصف الحادي عشر، حيث الدراس اختيرت

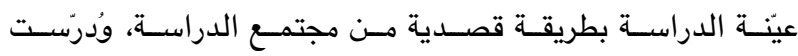

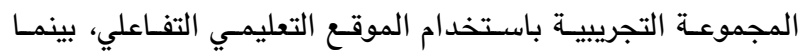

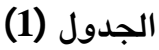

تصميم الدراسة

\begin{tabular}{|c|c|c|c|}
\hline التطبيق البعدي & نوع المعالجة & التطبيق القبلي التيل & 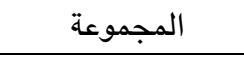 \\
\hline الاختبار التحصيلي & التدريس باستخدام الموقع التعليمي التفاعلي & الاختبار التحصيلي & المجموعة التجرييية \\
\hline مقياس التفكير البصري & التدريس بالطريقة المعتادة & مقياس التفكير البصري & المجموعة الضابطة \\
\hline
\end{tabular}

أ- مرحلة التحليل: وتتضمن تحديد الأهداف العامة للبرنامج،

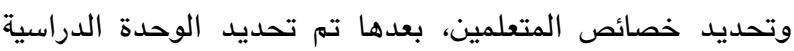

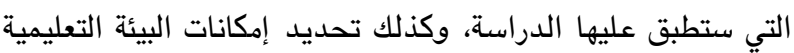

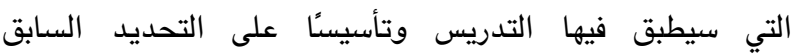

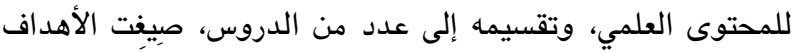

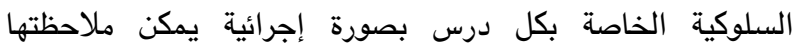

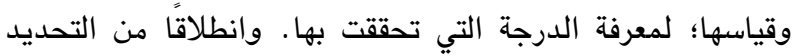

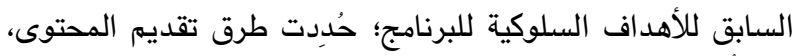

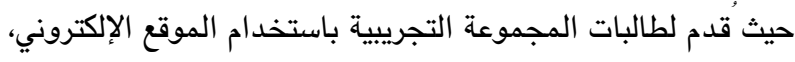
بينما قدم المحتوى للمجموعة الضابطة بالطريقة الاعتيادية.

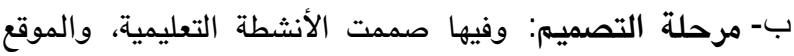

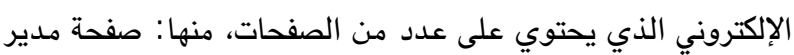

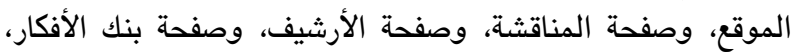

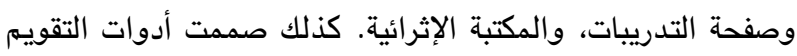

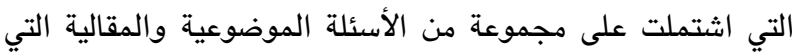

تأتي بعد الانتهاء من دراسة كل موضوع من موضوعات المادة. ج- مرحلة الإنتاج: وفيها أنتج الموقع التعليمي، وربط الموقع بأدوات التفاعل، ثم عمل له إخراج مبدئي.

د - مرحلة التقويم: قُسمت هذه المرحلة إلى ثلاث خطوات: 1. تقويم الأنثطة والمحتوى الذي رفع عبر الموقع الإلكتروني قبل تحويله إلى محتوى إلكتروني.

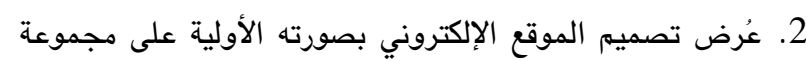

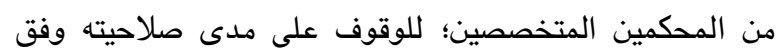

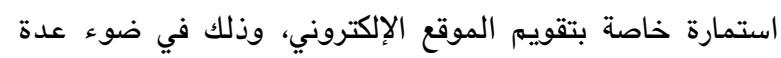

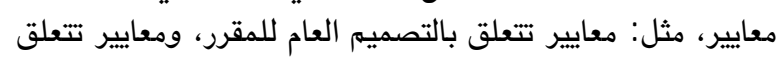

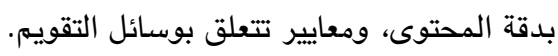

مجتمع الدراسة وعينتها - اس

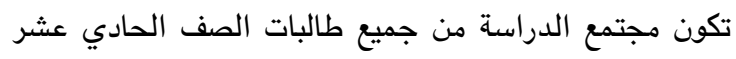

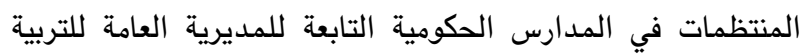

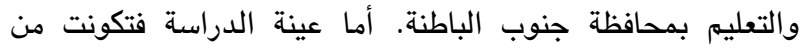
(62) طالبة من طالبات الصف الحادي عشر من مدرستين هما:

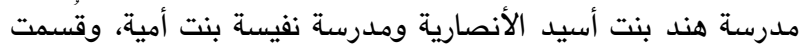

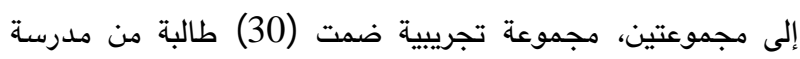

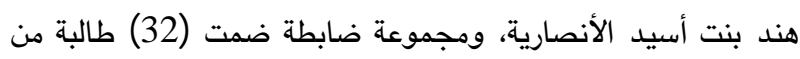
مدرسة نفيسة بنت أمية.

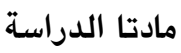

1. دليل المعله: أعد دليل للمعلمة للاستعانة به في تدريس وحدة

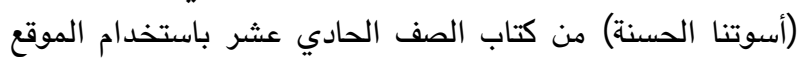

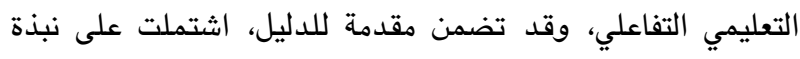

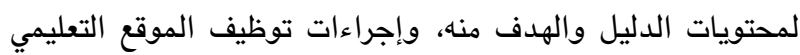

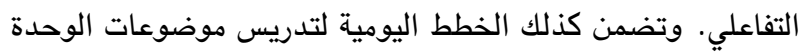

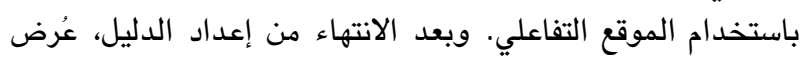

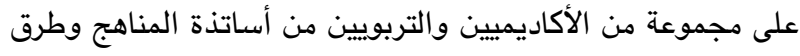

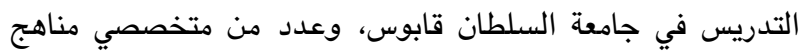

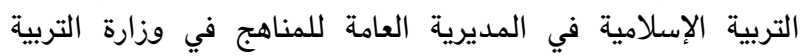

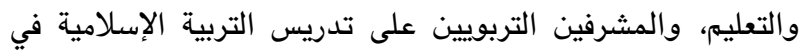

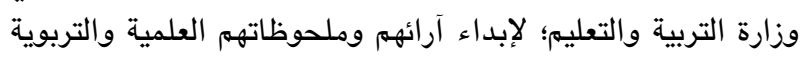

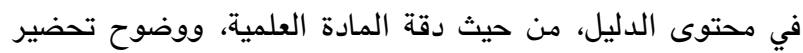

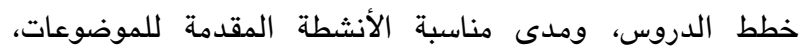

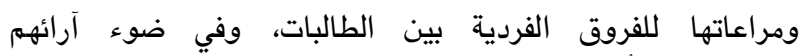
وملحوظاتهم، أُجريت التعديلات اللازمة.

2. الموقع التعليمي: صمم موقع تعليمي وفق أحد نماذج تصميم مواقع الإنترنت، واتبعت في ذلك المراحل موقع الآتية: 
من (20) سؤالاً. وأعطيت الدرجة (1) للإجابة الصحيحة عن كل

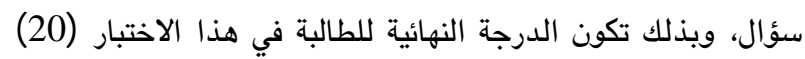

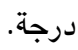

\section{ح · ثبات الاختبار}

للتحقق من ثبات الاختبار، طُبق على عينة استطلاعية مكونة

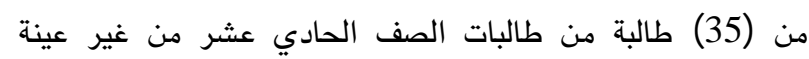

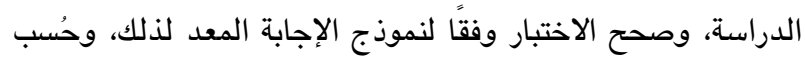

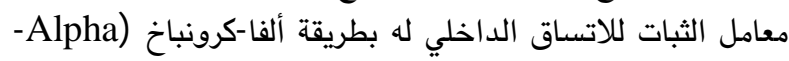

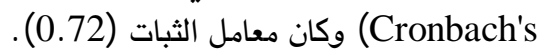

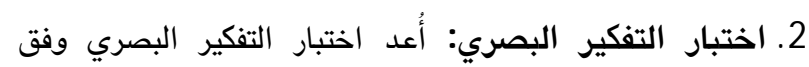

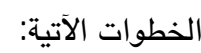

أ. تحديد الهدف من الاختبار: هدف اختبار مهارات التفكير

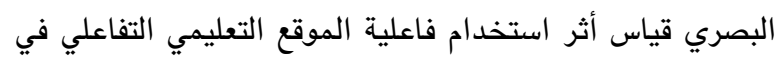

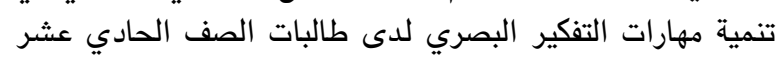

$$
\text { في مادة التربية الإسلامية. }
$$

ب. تحديد المهارات التي يقيسها الاختبار: تم تحديد المهارات

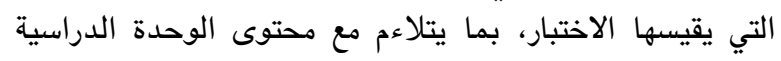

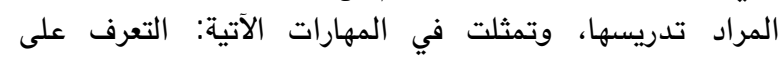

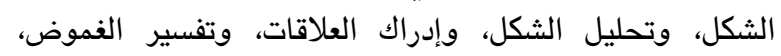

$$
\text { واستنتاج المعنى. }
$$

ج. صياغة أسئلة الاختبار: تكون الاختبار من (23) سؤالاً من

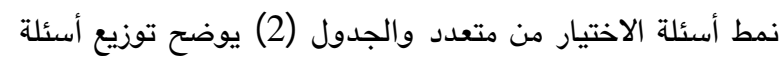

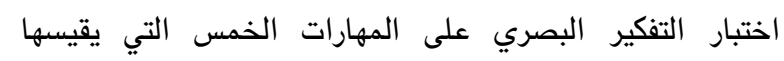
الاختبار . - الار

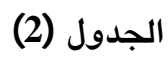

\begin{tabular}{|c|c|c|c|}
\hline النسبة & 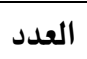 & الأسئلة & المهارة \\
\hline$\% 22$ & 5 & 1، 3، 4، 17، 18 & التعرف على الشكل \\
\hline$\% 27$ & 6 & 2، 7، 8، 13، 16، 21 & تحليل الشكل \\
\hline$\% 17$ & 4 & 5، 6، 15، 20 & إدراك العلاقات \\
\hline$\% 17$ & 4 & 9، 10، 12، 23 & تفسير الغموض \\
\hline$\% 17$ & 4 & 11، 14، 19، 22 & استتناج المعنى \\
\hline$\% 100$ & 23 & 23 & المجموع \\
\hline
\end{tabular}

توزيع أسئلة اختبار التفكير البصري على المهارات الخمس

$$
\text { صدق اختبار مهارات التفكير البصري }
$$

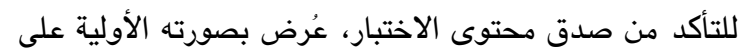

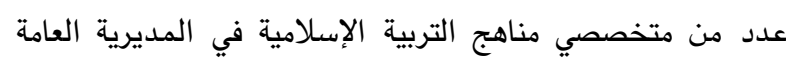

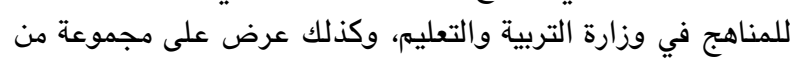
المشرفين التربويين الذين يشرفون على تدريس التربية والتئ وكذل الإسلامية في وزارة التربية والتعليه، إلى جانب مجموعة من معلمات الذرين التربية الاسلامية
3. التقويم في أثناء التطبيق، فكان لمعلمة المادة مع الطالبات

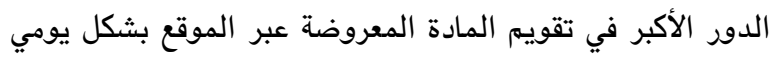
ومستمر طوال فترة التطبيق.

هـ مرحلة التنفيذ (التجريب): طُبتت حصة استطلاعية للوقوف

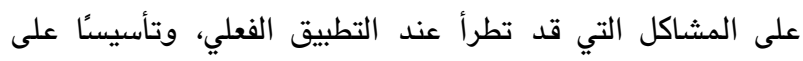

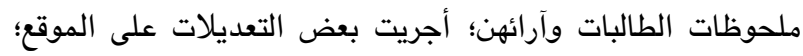

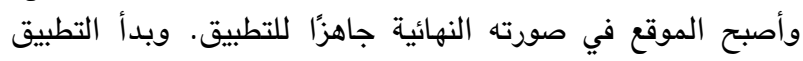

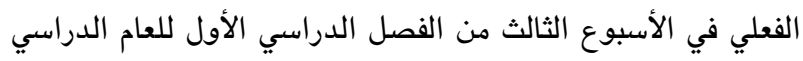

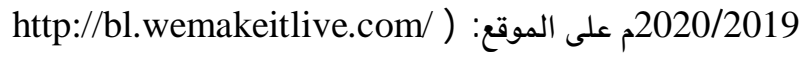
. (login.aspx ثانيًا: أداتا الدراسة 1. الاختبار التحصيلي: أُعد الاختبار التحصيلي وفق الخطوات

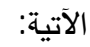

أ. تحديد الهدف من الاختبار: يهدف الاختبار إلى قياس تحصيل طالبات الصف الحادي عشر - وفق مستويات المجال الهال المعرفي

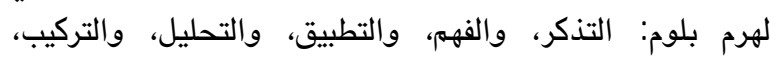

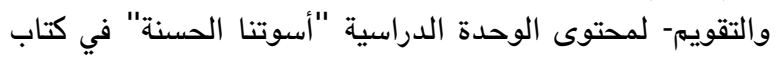

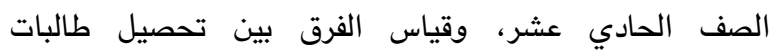
المجموعتين التجريبية والضابطة في الاختبار البعدي.

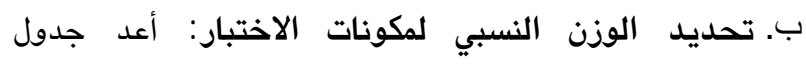

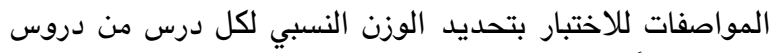

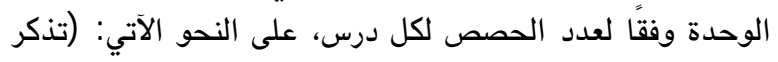

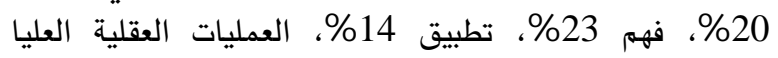
. $\% 43$

ج. صياغة فقرات الاختبار: وذلك باختبار نمط أسئلة الاختيار من الأن

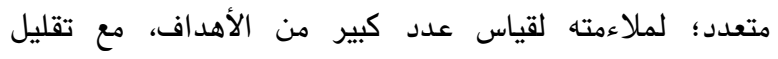

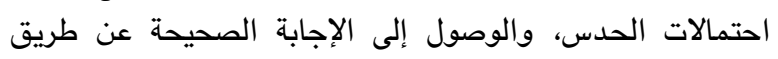

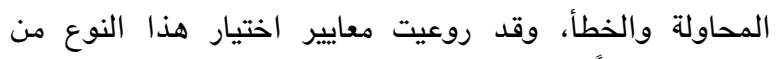
الأسئلة. وبناءً على ذلك، تضمن وقد الاختبار التحصيلي (20) سؤالاً.

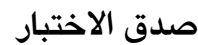

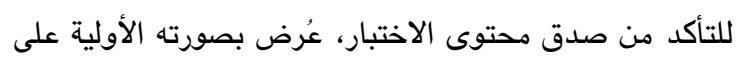

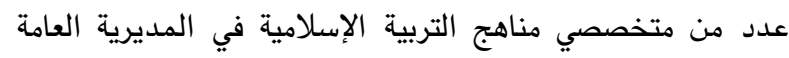

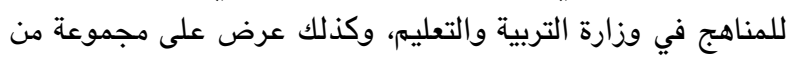

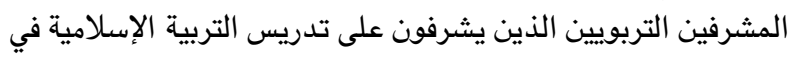

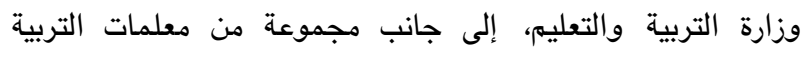

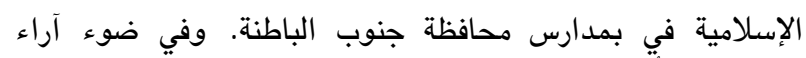

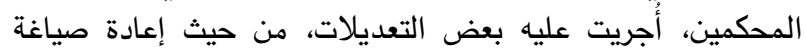

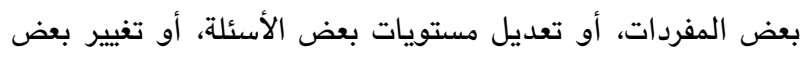
الصياغات اللغوية. وبذلك أصبح الاختبار في صورته النهائية مكوناً 
معامل الثبات للاتساق الداخلي له بطريقة بطريقة ألفا-كرونباخ Cronbach-Alpha) تكافؤ المجموعتين في الاختبار التحصيلي واختبار مهارات التفكير البصري

للتأكد من تكافؤ مجموعتي الدراسة في الاختبار التحصيلي

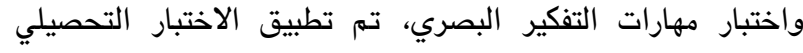

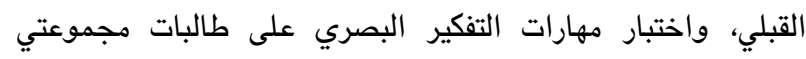

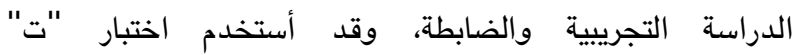

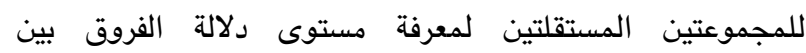

المجموعتين، فكانت النتائج كما هو موضح في الجدول (3) .
الإسلامية في مدارس محافظة جنوب الباطنة وفي ضوء آراء

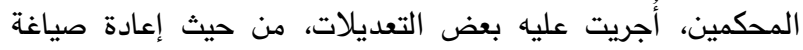
بعض الأسئلة، وتغيير بعض الصور واليه بعض الأشكال لعدم وضوحها، وتغييير

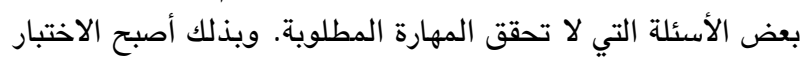

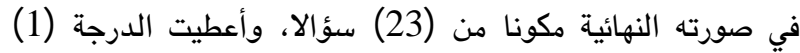

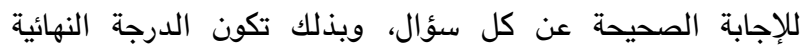
للطالبة في هذا الاختبار (23) درجة.

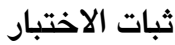

للتحقق من ثبات الاختبار، طُقق على عينة استطلاعية مكونة من (37) طالبة من طالبات الصف الحادي عشر من غئل غير عينة

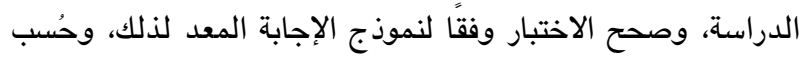

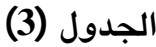

\begin{tabular}{|c|c|c|c|c|c|c|c|c|}
\hline \multirow{3}{*}{ مستوى } & \multirow{3}{*}{ "تيمة } & \multirow{3}{*}{ الحرية } & \multicolumn{2}{|c|}{ المجموعة الضابطة } & \multicolumn{2}{|c|}{ المجموعة التجريبية } & \multirow{3}{*}{\multicolumn{2}{|c|}{ الأداة }} \\
\hline & & & \multirow{2}{*}{ المعياري } & \multirow{2}{*}{ الحسابي } & \multirow{2}{*}{ المعياري } & \multirow{2}{*}{ المستوسط } & & \\
\hline & & & & & & & & \\
\hline 0.697 & 0.392 & 60 & 4.38 & 11.40 & 3.47 & 11.00 & التحصيلي القبلي & الاختبا \\
\hline 0.279 & 1.092 & 60 & 0.76 & 3.47 & 0.69 & 3.27 & التعرف على الشكل & \\
\hline 0.291 & 1.065 & 60 & 0.93 & 2.97 & 0.76 & 3.20 & تحليل الثكل & اختبار ** \\
\hline 0.209 & 1.270 & 60 & 0.89 & 2.95 & 0.72 & 3.23 & إدراك العلاقات & مهارات \\
\hline 0.105 & 1.648 & 60 & 1.30 & 2.72 & 0.74 & 3.17 & تفسير الغموض & التفكير \\
\hline 0.609 & 0.514 & 60 & 1.07 & 2.22 & 0.60 & 2.33 & استنتاج المعنى & البصري \\
\hline 0.485 & 0702 & 60 & 2.10 & 14.03 & 1.60 & 14.36 & الاختبار الكلي & \\
\hline
\end{tabular}

3. التطبيق القبلي لأداتي الدراسة على طالبات المجموعتين التجريبية والضابطة، لقياس مدى التكاني التكافؤ بينهما. 4. البدء في تطبيق الدراسة بتاريخ 2019/9/22م.

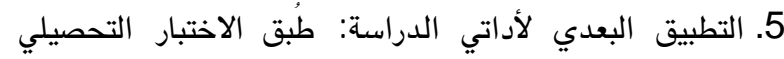

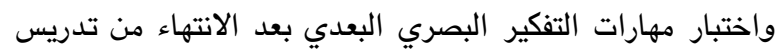
الوحدة. النتائج ومناقشتها أولًا: النتائج المتعلقة بالسؤال الأول: " ما فاعلية استخدام موقع

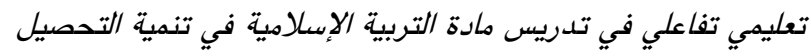

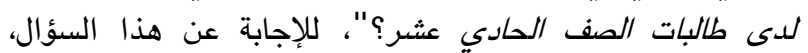

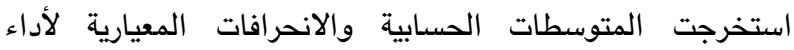

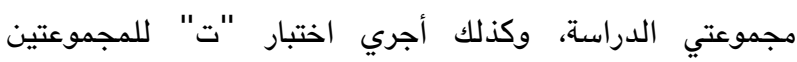
المستقلتين، وذلك للتحقق من دلالة الفروق بين المجموعتين

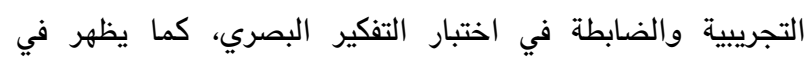

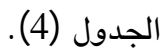

يتضح من الجدول (3) أن قيمة "ت" للفرق بين المتوسطين

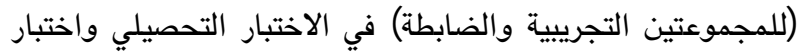

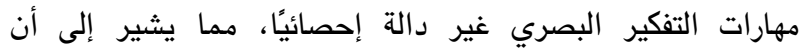
المجموعتين متكافئتان في الأداتين. الإجراءات اتبعت في تطبيق الدراسة الإجراءات الآتية: 1. الحصول على الموافقة الرسمية من المكتب الفني للدراسات والتطوير في وزارة التربية والتعليم لتطبيق الدراسة.

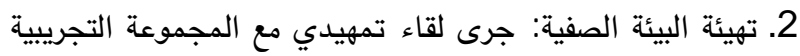

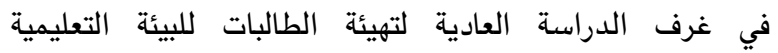
الجديدة، حيث سيدرسن محتوى الوحدة الرابعة (أسوتنا

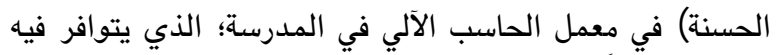

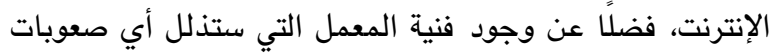

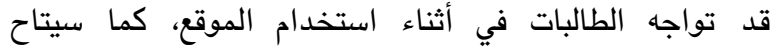

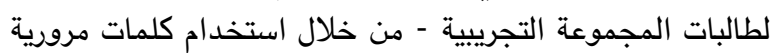
لكل طالبة - الدخول إلى الموقع في الأوقات المناسبة لهن. 
(4) الجدول

المتوسطات الحسابية والانحرافات المعيارية وقيمة (ت) لدرجات المجموعتين التجريبية والضابطة في اختبار التحصيل الدراسي البعدي

\begin{tabular}{|c|c|c|c|c|c|c|c|}
\hline حجم الأثر & مستوى الدلالة & (لميمة "ت المحسوية & المعياري الانحراف & المتوسط الحسابي & المجموعة & الد = (62) الدرجة & الأداة \\
\hline \multirow[t]{2}{*}{0.34} & 0.000 & 5.611 & 4.64 & 22.10 & التجريبية & 30 & الاختبار \\
\hline & & & 3.45 & 16.17 & الضابطة & 32 & التحصيلي \\
\hline
\end{tabular}

بالمحتوى، كل ذلك من شأنه تنمية التحصيل الدراسي في

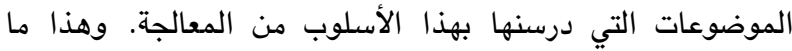

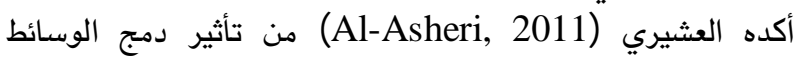

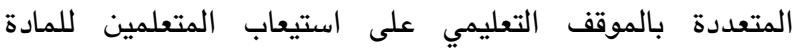

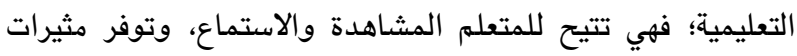

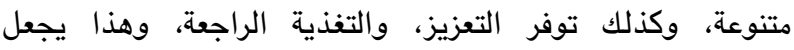

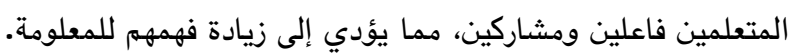

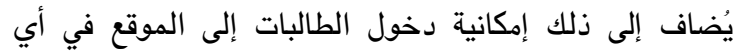

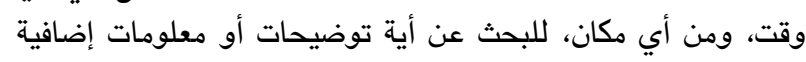

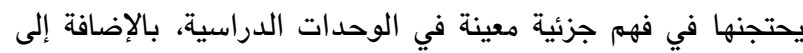

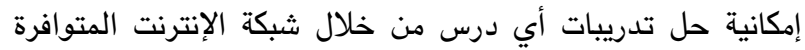

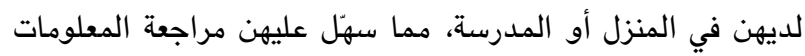

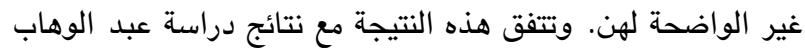

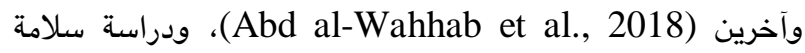

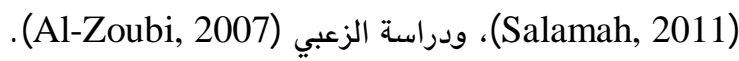

ثانيًا: النتائج المتعلقة بالسؤال الثاني:" ما فاعلية استخدام موقع

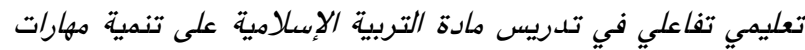

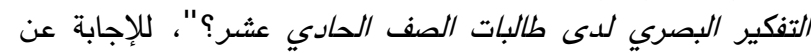

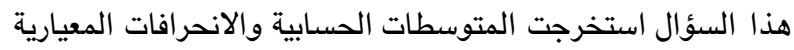

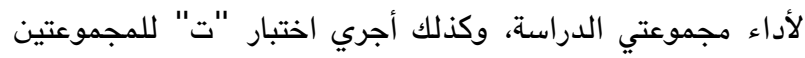

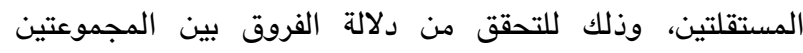

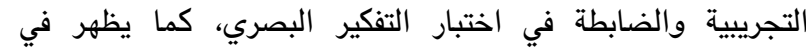

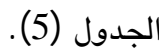

تشير النتائج في الجدول (4) إلى وجود فرق دال إحصائيًا

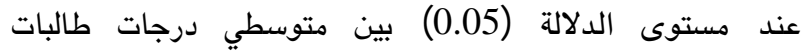

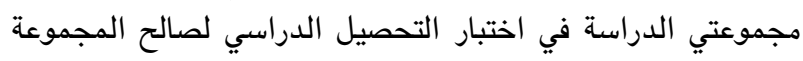

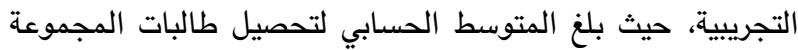

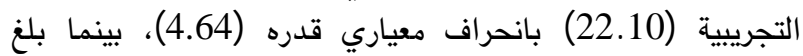

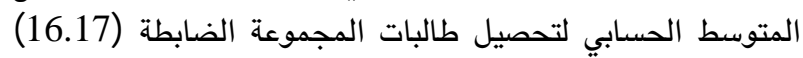

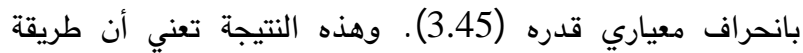

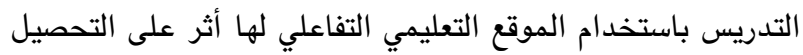

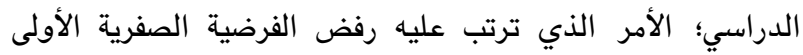

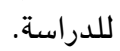

ويبين الجدول نفسه أن حجم الأثر لاستخدام الموقع التعليمي

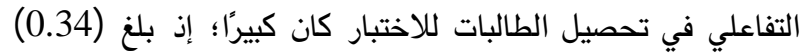

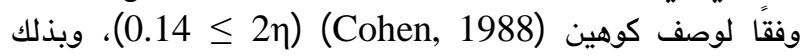

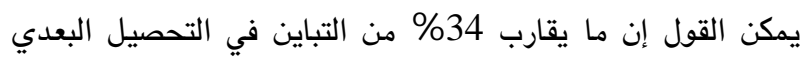
يرجع لاستخدام الموقع التعليمي التفاعلي.

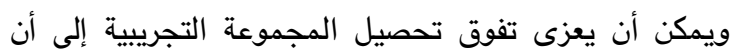
عرض الوحدة الدراسية على الموقع الإلكتروني أدى إلى توفير توفي بيئة

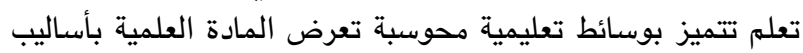

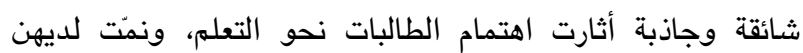

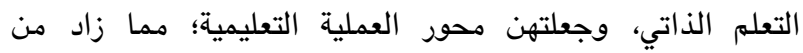

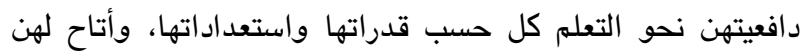

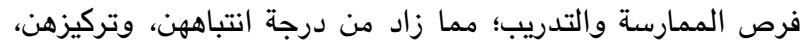

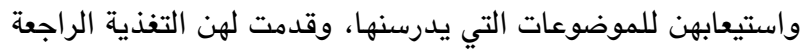

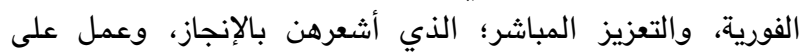

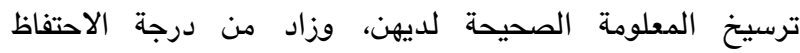




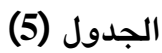

\begin{tabular}{|c|c|c|c|c|c|c|c|c|}
\hline حجم الأثر & مستوى الدلالة & قيمة "ت المحسوية & درجة الحرية & الالمعراف & الحسابي & المجموعة & الدرجة الكلية & المهارة \\
\hline \multirow{2}{*}{0.20} & \multirow{2}{*}{0.000} & \multirow{2}{*}{3.886} & 60 & 0.714 & 4.20 & التجريبية & \multirow{2}{*}{5} & \multirow{2}{*}{ التعرف على الشكل } \\
\hline & & & 60 & 1.215 & 3.20 & الضابطة & & \\
\hline \multirow{2}{*}{0.07} & \multirow{2}{*}{0.039} & \multirow{2}{*}{2.129} & 60 & 0.935 & 4.57 & التجريبية & \multirow{2}{*}{6} & \multirow{2}{*}{ تحليل الثكل } \\
\hline & & & 60 & 1.929 & 3.73 & الضابطة & & \\
\hline \multirow{2}{*}{0.13} & \multirow{2}{*}{0.003} & \multirow{2}{*}{3.106} & 60 & 0.621 & 3.60 & التجريبية & \multirow{2}{*}{4} & \multirow{2}{*}{ إدراك العلاقات } \\
\hline & & & 60 & 0.928 & 2.97 & الضابطة & & \\
\hline \multirow{2}{*}{0.09} & \multirow{2}{*}{0.016} & \multirow{2}{*}{2.474} & 60 & 0.809 & 3.37 & التجريبية & \multirow{2}{*}{4} & \multirow{2}{*}{ تفسير الفموض } \\
\hline & & & 60 & 1.322 & 2.67 & الضابطة & & \\
\hline \multirow{2}{*}{0.07} & \multirow{2}{*}{0.033} & \multirow{2}{*}{2.179} & 60 & 0.844 & 2.67 & التجريبية & 4 & \multirow{2}{*}{ استتتاج المعنى } \\
\hline & & & 60 & 1.042 & 2.13 & الضابطة & & \\
\hline \multirow{2}{*}{0.23} & \multirow{2}{*}{0.000} & \multirow{2}{*}{4.343} & 60 & 1.905 & 18.40 & التجريبية & \multirow{2}{*}{23} & \multirow{2}{*}{ الاختبار ككل } \\
\hline & & & 60 & 4.260 & 14.70 & الضابطة & & \\
\hline
\end{tabular}

*دال إحصائيًا عند مستوى الدلالة (0.05) .

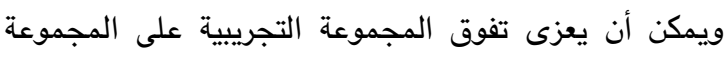

الضابطة في مهارات التفكير البصري والاختبار ككل إلى الآتي:

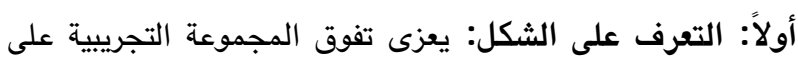

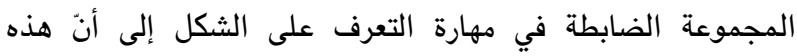

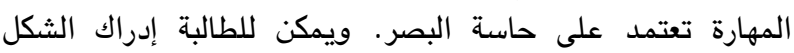

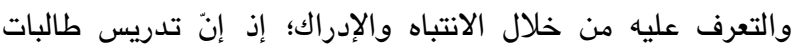

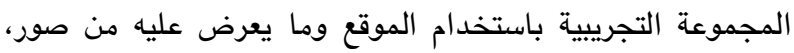

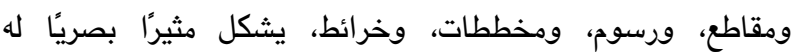

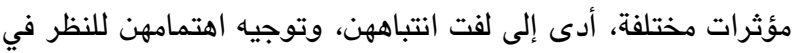

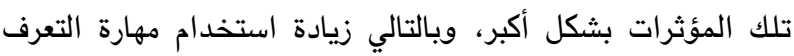

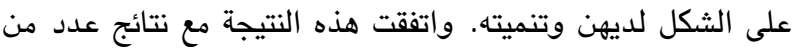

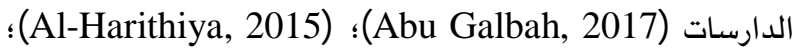

(Al Astal, 2014)؛ (Zangour, 2014)

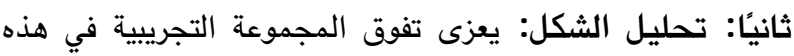

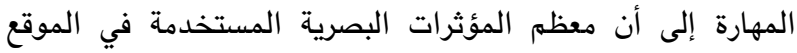
يطلب فيها إلى الطالبات أن يقمن بتحليلها ومعرفة التفات التفاصيل الخاصة التهات

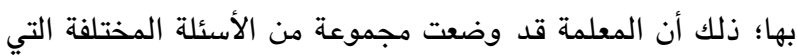

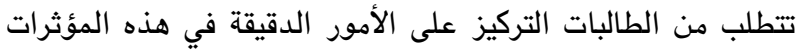

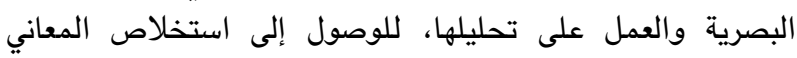

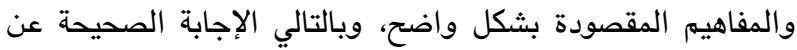

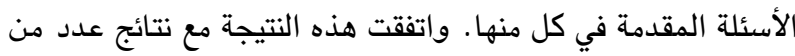

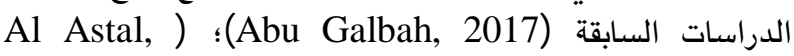

2014)؛ (Al-Harithiya, 2015)
تشير النتائج في الجدول (5) إلى فروق ذات دلالة إحصائية

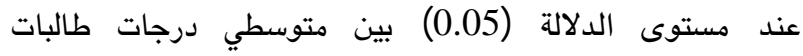

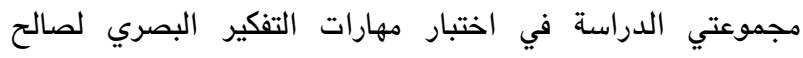

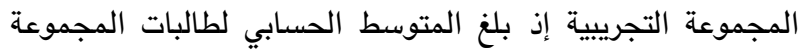

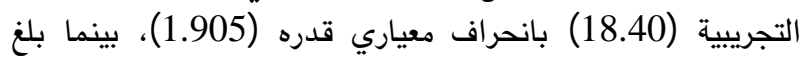

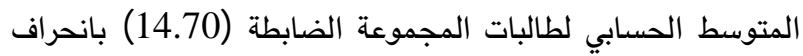

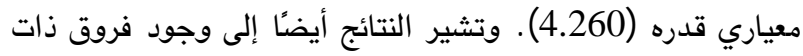

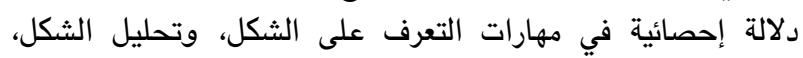

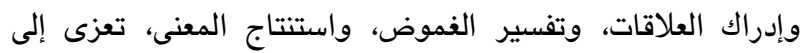

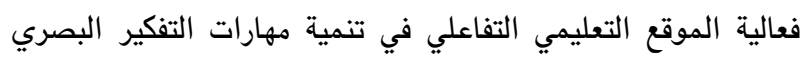
لصالح طالبات المجموعة التجريبية.

ويبين الجدول (5) أن حجم الأثر لاستخدام الموقع التعليمي

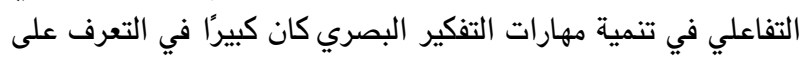

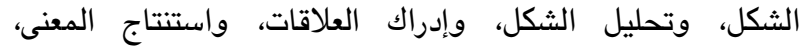
والاختبار ككل؛ لأن ما يفسره المتغير المستقل (الموقع التعليمي

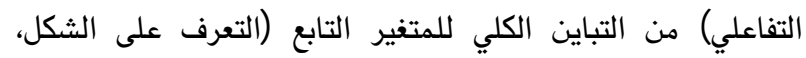

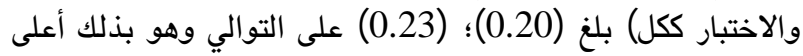

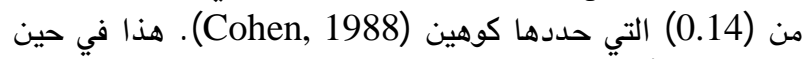

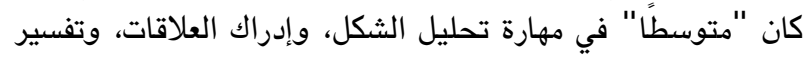

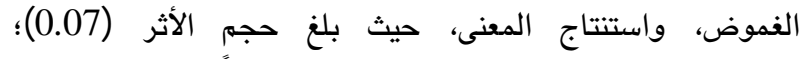

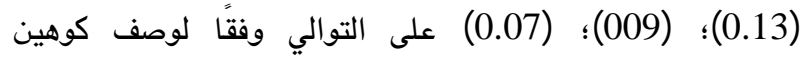
(Cohen, 1988) 
العلمية؛ فهي تبدا بجذب الطالبات ولفت انتباههن نحو الصور ومقاطع الفيديو والرسوم والقصص المعروضة، تم التأمل والتفكير

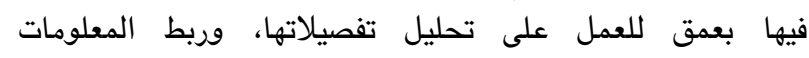

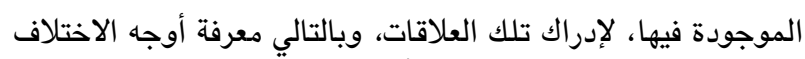

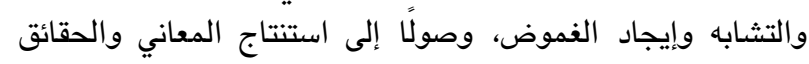
المقصودة، كما أن الطالبات في أثناء إجابتهن عن الأنثطة والثة وأسئلة

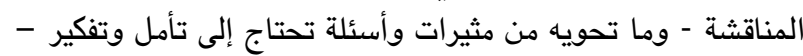

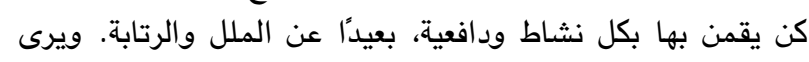
الباحثان أن إتاحة الفرصة للطالبات للتعبير بحرية عن أفكارهن كتابيًا

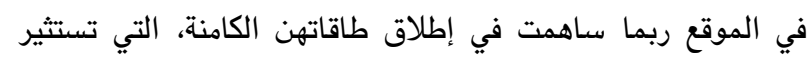

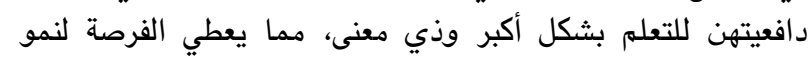

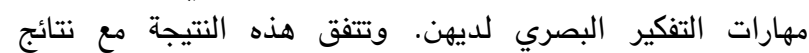

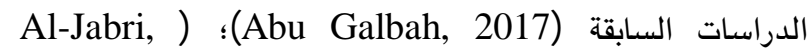
2017)؛ (Zangour, 2014) (لدرات (1) التوصيات

في ضوء النتائج التي خلصت إليها الدراسة، توصي بالآتي: • نشر ثقافة تفعيل المواقع التعليمية التفاعلية المختلفة بين الطلبة، وتوبة وتوضيح أهميتها وفاعليتها في توفير بيئة تعليمية غنية ومشجعة . • عقد ورش تدريبية لمشرفي التربية الإسلامية ومعلميها؛ لتعريفهم

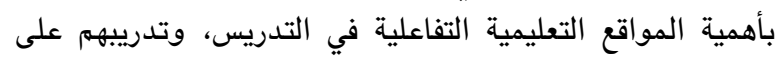
تصميمها وطرق توظيفها في كل مرحلة من المراحل التعليمية. • إجراء دراسة عن فاعلية استخدام موقع تعليمي تفاعلي في

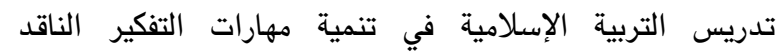
والابتكاري والأخلاقي في مراحل دراسية مختلفة. • إجراء دراسة أثر استخدام المواقع القائمة على تقنيات الجيل الثاني للويب في تنمية مهارات أخرى للمعلمين والمتعلمين.
ثالثًا: إدراك العلاقات: تعدّ هذه المهارة من المهارات التي تحتاج

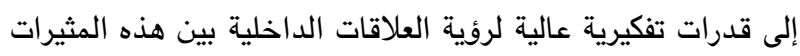

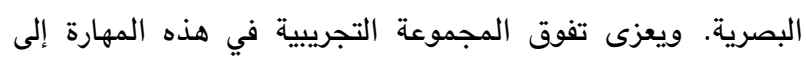

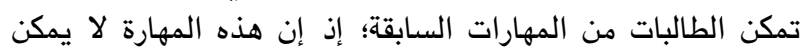

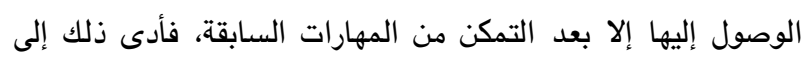

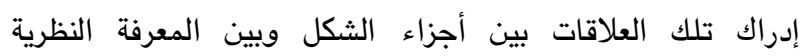
المرتبطة به ويين النتائج؛ ما أدى إلى تفوق الملاحظة وزياءتهاء الدها، والدقة في الإدراك. وقد ساعد الموقع على تحقيق ذلك عبر التركيز

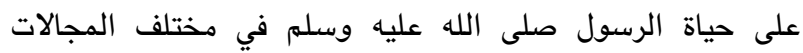

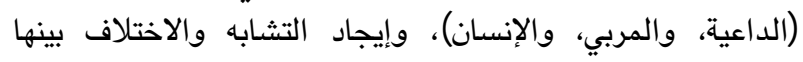

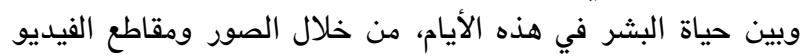

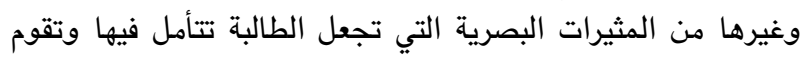

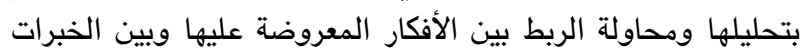

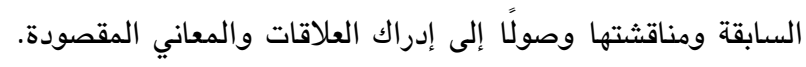

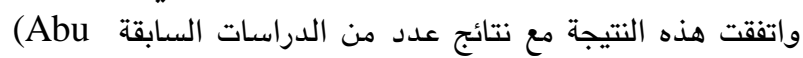
Al Astal, ) (Al-Busaidia, 2017) (Galbah, 2017)

. (2014

رابعًا: تفسير الفموض: تعبر هذه المهارة عن القدرة على توضيح

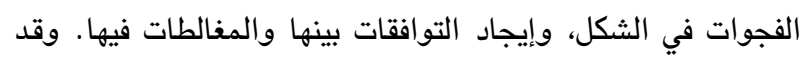

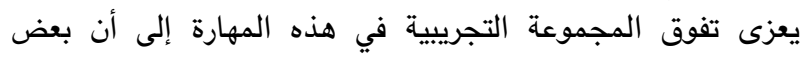
الأنشطة المقدمة فيها صممت بشكل يثير فضول الطالبات وحبهن فئن

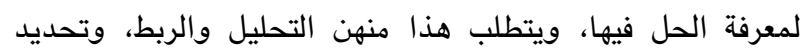

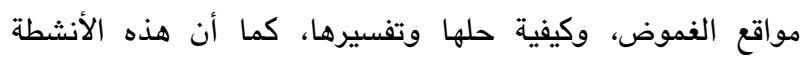

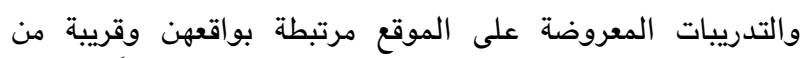

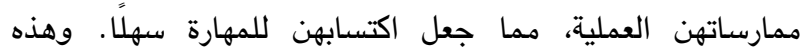

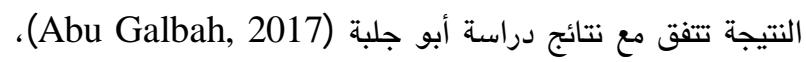

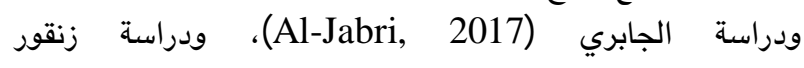
. (Zangour, 2014)

خامسيًا: استنتاج المعنى: تعبر هذه المهارة عن القدرة على

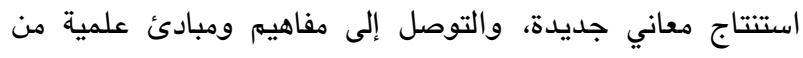
خلال الثكل المعروض، مع مراعاة تضمين هذه المهارة مع المهارات

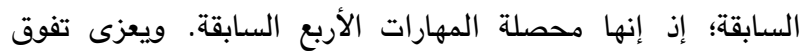

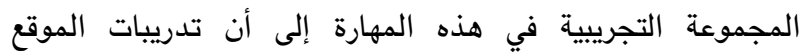

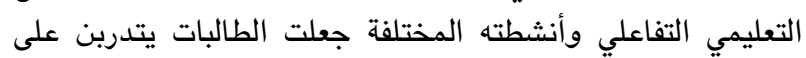
خطوات منهجية معينة، وصولًا إلى استنتاج المفاهيم والخطية الخطوات 


\section{References}

Abd al-Wahhab, J., Ajwa, S., \& Atiyah, I. (2018). A program based on blended learning in Islamic education to develop ethical values needed for high-school students. Journal of the College of Education, 29(116), 121-184.

Abdel-Gawad, B. (2014). Academic achievement more effective with information technology. Al-Ahram Foundation.

Abdel-Khalek, R., \& Abdel-Khalek, A. (2008). Educational technology and its modern techniques. Dar Alnahdah Alhadithah.

Abu Darb, A. (2014). The effectiveness of using an interactive website for the development of cognitive achievement and visual thinking in social studies among preparatory-cycle students. Culture and Development, 15(83), 109-172.

Abu Galbah, N. (2017). The impact of the webQuest strategy in developing visual thinking in the mathematics course among middle-school students in Riyadh city. Journal of Educational and Psychological Sciences, 1 (5), 38-56.

Abu Khousa, A. (2014). The impact of implementing (K. W. L. H.) strategies and conceptual schemes on the development of thinking skills in technology at eleventh-grade students in Gaza. Unpublished Master Thesis. Islamic University, Palestine.

Abu Sharia, Z.(2015). The effect of teaching Islamic education on achievement and the development of creative thinking. Guidance of Islam: Ministry of Awqaf Islamic Affairs and Holy Places, 59(4), 64-73.

Al Agha, M. (2015). The effectiveness of virtualreality technology in developing visual thinking among ninth-grade students in Gaza. Master Thesis. Islamic University, Palestine.

Al-Asheri, H. (2011). Educational multimedia technology in the twenty-first century. Dar Alkitab Aljami'i.

Al Astal, W. (2014). The effectiveness of employing comics in academic achievement and visual thinking skills for fifth-graders in basic science in Khan Yunis. Master Thesis. AlAzhar University, Palestine.
Al Rumhi, A. (2017). The effectiveness of visual thinking in teaching Islamic education in the achievement of eleventh-grade students in the Sultanate of Oman and their retention of the academic subject. Muscat: The Ministry of Education.

Al-Ajamiyah, A. (2015). The effectiveness of using an interactive educational website in teaching social studies in developing achievement and critical thinking among tenth-grade students in the Sultanate. Master Thesis. Sultan Qaboos University, Sultanate of Oman.

Al-Amri, Z., Ali, K., \& Al-Shabani, A. (2016). Instructional-learning design according to the strategies of cognitive burden and its effect on the achievement of chemistry and visual thinking for fourth-year scientific students. The Eighteenth Scientific Conference: Curricula of Science between Egyptian and International. The Egyptian Association for Scientific Education, Cairo: Sheikh Saleh Kamel Center-Al-Azhar University, 215-236.

Al-Busaidia, N. (2017). The impact of using informatics on developing visual thinking and academic achievement for grade 11 students in biology subject. Master Thesis. Sultan Qaboos University, Sultanate of Oman.

Al-Duhani, F. (2012). The effectiveness of using an interactive educational website in acquiring astronomical concepts, modifying alternative perception, and developing attitudes towards astronomy among grade 5 students. Master's Thesis. Sultan Qaboos University, Sultanate of Oman.

Al-Harbi, F. (2018). The effect of mental maps strategy on developing visual thinking skills in mathematics course for grade 6 students. The Sixteenth Annual Scientific Conference: Developing Mathematics Education and Learning to Achieve the Quality Culture. The Egyptian Association for Mathematics Education, Cairo: Banha University, Faculty of Education, 115 - 139.

Al-Harithiya, S. (2015). The impact of teaching with guided imagination on developing visual thinking skills and achievement among grade 5 students in science subject. Master Thesis. Sultan Qaboos University, Sultanate of Oman. 
Ali, A. (2006). Educational website production: A contemporary educational vision and models in online education. Cairo: The World of Books.

Al-Jabri, F. (2017). The impact of using cartoons on the academic achievement and development of visual thinking skills in science subject among Grade 5 students. Master Thesis. Sultan Qaboos University, Sultanate of Oman.

Al-Jadhmi, Fa., \& Al-Bahriya, S. (2009). The reality of using educational computer and its obstacles in teaching Islamic education in the first cycle of basic education from female teachers' point of view: Research abstract; Master Thesis. Educational Development Journal, 8(51), 16-17.

Al-Khatib, H. (2008). The effectiveness of an interactive educational website on the achievement of biology: An experimental study for second-year secondary school students in Quneitra governorate. Master Thesis. Damascus University, Syria.

AL-Khazndar, N., \& Mahdi, H. (2006). The effectiveness of a website on visual and systemic thinking in multimedia among students of the Faculty of Education at AlAqsa University. The Eighteenth Scientific Conference: Education Curricula and Building Arab Thinking. Ain Shams University - The Egyptian Association for Curricula and Teaching Methods, Vol.2, Cairo: The Egyptian Association for Curricula and Teaching Methods, 620-645.

Al-Liqāni, A., \& Al-Jamal, A. (2003). Glossary of educational terms defined in curricula and teaching methods. Cairo: The World of Books.

Al-Qahtani, B. (2015). The effect of using the systemic approach in teaching biology on developing conceptual assimilation and visual thinking skills for second-year high-school students in Abha. Doctoral Thesis. Umm AlQura University, Kingdom of Saudi Arabia.

Al-Salkhi, M. (2014). Difficulties in teaching Islamic education from the viewpoint of lower secondary-school teachers in the city of Amman. Educational Journal, Kuwait University, Academic Publication Council, 29(113), 81-134.
Al-Saqriyah, R. (2018). The effectiveness of teaching using digital story in an integrated learning environment in the achievement of grade 11 students in Islamic education subject and developing their moral reasoning. Dirasat: Educational Sciences. University of Jordan, Deanship of Scientific Research, 45(3), 179-194.

Alsenaidi S. (2014). Designing interactive multimedia learning environments at the college of applied science in Oman. Society for Information Technology \& Teacher Education International Conference, 1, 20512054.

Al-Shawadfi, A. (2011). A suggested educational design for an interactive website in social studies and its effect on developing critical thinking and some online communication skills for seventh-grade students in basic education. Journal of the Educational Association for Social Studies - Egypt, 31, 14105.

Al-Shwiki, F. (2010). The effect of employing the systemic approach on the development of concepts and visual thinking skills in physics among eleventh-grade students. Master Thesis. Islamic University, Palestine.

Al-Smalouti, A. (2013). The effectiveness of using a suggested interactive educational website in the achievement and development of mathematical thinking among prep students. Arab Studies in Education and Psychology: Association of Arab Educators, 36(1), 97-124.

Al-Tarawnah, M. (2014). The effect of using circular house shape strategy on developing visual thinking among ninth graders in physics. Educational Sciences, 2(41), 789808.

Al-Zoubi, K. (2007). The effect of using an educational website on the achievement of grade 9 students in Islamic education in Jordan and their attitudes towards it. Doctoral Thesis. The University of Jordan, Jordan.

Barak, M., \& Ziv, S. (2013). Wandering: A webbased platform for the creation of locationbased interactive learning objects. Computers \& Education, 62, 159-170. 
Draz, W. (2007). The effect of teaching using visual thinking activities on solving engineering problems and developing visual thinking skills. Master Thesis. Sultan Qaboos University, Sultanate of Oman.

Ibrahim, A. (2006). The effectiveness of using visual thinking networks in science to develop Janet's levels of knowledge and visual thinking skills among middle-school students. The Tenth Scientific Conference, Scientific Education: Current Challenges and Future Visions. Ain Shams University, College of Education, The Egyptian Association for Scientific Education, Volume 1, Ismailia, 73135.

Jabr, Y. (2010). The effect of employing postcognitive learning strategy in developing visual thinking skills concepts in sciences among grade 10 students. Master Thesis. Islamic University, Palestine.

Mahdi, H. (2006). The effectiveness of using educational software in visual thinking and achievement in information technology among eleventh-grade students. Master Thesis, Islamic University, Palestine.

Mohamed, H. (2015). Using thinking maps to develop achievement and some visual thinking skills among students of the Faculty of Specific Education. Arab Studies in Education and Psychology, 57, 203-248
Salamah, I. (2011). Designing an educational website and measuring its impact on the achievement of Islamic education curriculum students at Al Al-Bayt University. Al-Manara Journal for Research and Studies. 17(7), 97118.

Saleh, M. (2012). Evaluating the content of science books in the intermediate stage in light of visual thinking skills and the extent to which students acquire them. Arab Studies in Education and Psychology, 32, 13-45.

Sharp, S. (2000). Internet usage in education. Technological Horizons in Education. 27(10), 12-14.

Shehata, H., Al-Najjar, Z., \& Ammar, H. (2003). Glossary of the educational and psychological terms. Cairo: Aldaar Almisriah Allubnaniah.

Suwaidan, S., \& Ismail, F. (2019). The effect of using thinking maps in visual thinking among grade 4 female students (literary branch) in the Holy Quran and Islamic Education subject. Journal of the University of Anbar for Humanities, University of Anbar, 1, 424-446.

Zangour, M. (2014). An interactive educational website in light of e-learning management systems and its impact on developing visual perception skills and generating information for mentally-skilled primary students with learning difficulties in mathematics in the Kingdom of Saudi Arabia. Mathematics Pedagogies Journal, Egyptian Association for Mathematics, 17(5), 6-130. 